\title{
Serial Cost Sharing in Multidimensional Contexts*
}

\author{
Cyril Téjédo ${ }^{\dagger} \quad$ Michel Truchon ${ }^{\ddagger}$
}

cahier 0108

cahier 01-07

du Centre de Recherche en Économie et Finance Appliquées CRÉFA

September 26, 2001

\footnotetext{
${ }^{*}$ We thank Patrick González, Philippe Mahenc, Michel Moreaux, François Salanié, Yves Sprumont, and Yuntong Wang for their helpful comments. We also thank the Institut d'économie industrielle de l'Université des Sciences Sociales de Toulouse for its hospitality during the Fall 1999.

†GRÉMAQ, Toulouse; CIRANO; CRÉFA, and Département d'économique, Université Laval; email: ctej@ecn.ulaval.ca

${ }_{\ddagger}^{\ddagger}$ CIRANO; CRÉFA, and Département d'économique, Université Laval; email: mtru@ecn.ulaval.ca
} 


\section{Contents}

1 Introduction $\quad 1$

2 Overview of the paper $\quad 2$

3 The Cost Sharing Problem 4

3.1 The demands . . . . . . . . . . . . . . . . . . . 5

3.2 The cost function . . . . . . . . . . . . . . . . . . . 5

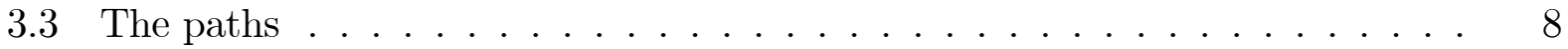

3.4 Special cases . . . . . . . . . . . . . . . . . . . . . . . . . . . . . . . . . . . . . . . . .

3.5 An example . . . . . . . . . . . . . . . . . . . 10

4 The Path Serial Cost Sharing Rule $\quad 12$

5 Properties of Cost Sharing Rules 15

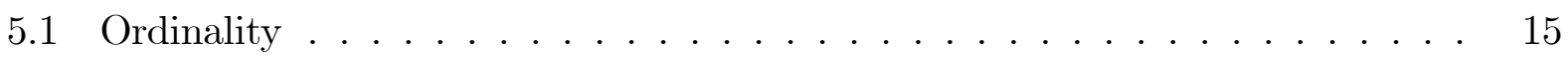

5.2 Equal Treatment of Equivalents . . . . . . . . . . . . . . . . . . 17

5.3 The Serial Principle . . . . . . . . . . . . . . . . . . 18

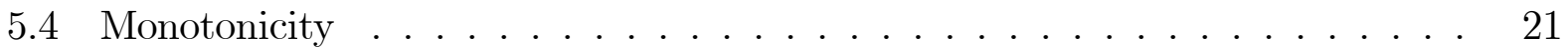

5.5 Bounds for Cost Shares . . . . . . . . . . . . . . . . . . 23

5.6 Separation and Additivity . . . . . . . . . . . . . . . 25

6 Characterization of the Path Serial Rule $\quad 26$

$\begin{array}{llr}7 & \text { Conclusion } & 28\end{array}$

8 Proofs $r$

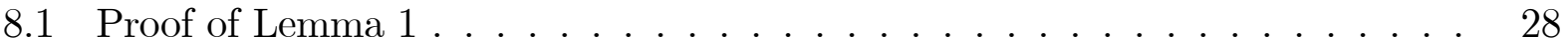

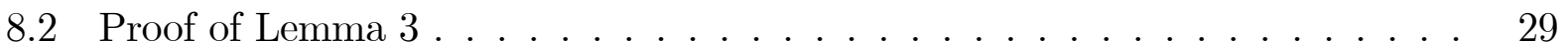

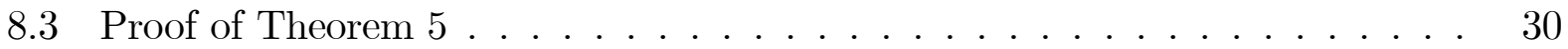

8.4 Proof of Theorem $6 \ldots \ldots \ldots \ldots$. . . . . . . . . . . . . . . . . . . . . . . . . . . . . . . .

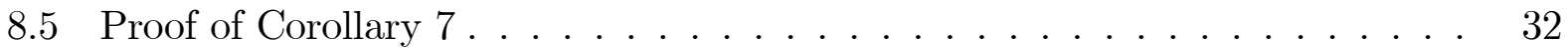

8.6 Proof of Theorem $8 \ldots \ldots \ldots . \ldots \ldots \ldots$

8.7 Proof of Theorem $9 \ldots \ldots . \ldots \ldots$

8.8 Proof of Theorem $15 \ldots \ldots . \ldots \ldots$

8.9 Proof of Theorem $17 \ldots \ldots \ldots \ldots$

8.10 Proof of Theorem $18 \ldots \ldots \ldots$ 


\begin{abstract}
The Serial Cost Sharing Rule was originally conceived for situations where the demands of agents pertain to a homogeneous private good, produced by an unreplicable technology. In this context, it is endowed with a variety of desirable equity and coherency properties. This paper investigates the extension of this rule to the context where agents request many goods that may be public, private or specific to some of them, where the aggregation rule may be very general and where demands may have to be scaled in a non proportional way, more precisely along a path, in order to compute cost shares. It proposes the Path Serial Rule to address these general problems. It then shows which properties and characteristics are satisfied by this rule. Some of them are transposed directly from the single good context to the general one while other must be weakened. More precisely, they are required to hold only on the paths along which demands must be scaled if needed. Nevertheless, some of the characterisations of the serial rule in the single good case do not carry over to the general context.
\end{abstract}

Keywords: Serial cost sharing, multi products, general aggregation.

JEL Classification: D63, C71

\title{
Résumé
}

La règle de partage séquentiel des coûts a été conçue à l'origine pour le cas où les demandes des agents portent sur un bien privé homogène, produit par une technologie non reproductible. Dans un tel contexte, cette règle satisfait de nombreuses propriétés d'équité et de cohérence. Dans cet article, on étudie l'extension de cette règle aux cas où les demandes des agents peuvent être des vecteurs qui ne représentent pas forcément des biens homogènes entre les agents, dont l'agrégation ne se fait pas uniquement via la sommation et où les demandes doivent être ajustées de manière non proportionnelle, plus précisément le long d'un sentier, pour le calcul des parts de coût. On montre ensuite quelles sont les propriétés qui sont satisfaites par cette règle ou qui la caractérisent. Certaines sont transposées directement du contexte à un seul bien au contexte général alors que d'autres doivent être affaiblies. Plus précisément, on exige leur respect uniquement le long des sentiers servant à ajuster les demandes le cas échéant. Néanmoins, certaines caractérisations de la règle séquentielle dans le contexte à un seul bien ne peuvent pas être transposées au contexte général. 


\section{Introduction}

The Serial Cost Sharing Rule has received much attention since its introduction by Shenker (1990) and its extensive analysis by Moulin and Shenker (1992, 1994). It was originally conceived for problems where $n$ agents request different quantities of a private good, the sum of which is produced by a single facility. This rule can be constructed from two ethical axioms: Equal Treatment of Equals (in terms of demands) and Independence of Larger Demands (a protection of small demanders against larger ones). It satisfies other interesting properties and has other characterizations as well. It is therefore natural to investigate whether this rule can be extended to more general problems while keeping similar properties.

Sprumont (1998) brings a partial answer to this question by proposing an extension of the Serial Rule for the case where each agent requests a single specific good. The Axial Serial Rule, as he calls it, also has an interesting characterization. Koster et al. (1998) propose a similar extension, the Radial Serial Rule, for the context where agents request several but homogeneous private goods. As its name implies, this rule uses intermediate demands that are constructed by changing the original demands in a proportional way.

None of the two problems considered by these authors is more general than the other. Our paper considers a more general context where each agent requests a list of goods that may be private, public, or specific to some agents and where aggregate demand is not necessarily the sum of individual demands. Moreover, we admit more general paths along which demands may be scaled down to construct intermediate demands. This yields a rule that we call the Path Serial Rule.

The paper presents a systematic analysis of this rule in the light of different properties found in the literature on cost sharing rules. These properties are transposed or extended to the general context whenever possible. Otherwise, they are weakened by requiring that the predicate holds only for changes in the demands taking place along the specified paths. It is shown that some of these properties are incompatible in the general context.

The Path Serial Rule is characterized by the Equal Treatment of Equivalent Demands (in terms of stand-alone costs) and the Path Serial Principle (a weaker form of Independence of Larger Demands). It also satisfies properties similar in spirit to the ones that hold for the original Serial Rule. However, a characterization in terms of other properties as found by Moulin and Shenker (1994) for the original rule or Sprumont (1998) for the Axial Rule seems impossible.

The paper is organized as follows. In Section 2, we review some of the known results on serial cost sharing and its generalization and in particular those of Kolpin (1996), Sprumont (1998) and Koster et al. (1998). We also give an overview of the paper. The formulation 
of the problem and the main definitions are given in Section 3. The section ends with an example illustrating the importance of the more general form of the problems to be considered. The Path Serial Cost Sharing Rule is defined in Section 4. The properties that can be imposed on a cost sharing rule are presented and extensively discussed in Section 5. The characterization of the Path Serial Rule in the general context is the object of Section 6. A brief conclusion follows as Section 7. Most proofs are collected in the last section.

\section{Overview of the paper}

With the original Serial Cost Sharing Rule, agents are ordered according to their demands. Then, the cost of producing $n$ times the demand of agent 1 , which is called an intermediate demand, is shared equally among all agents. In addition, agents 2 to $n$ must bear equally the incremental cost of another intermediate demand in which the demand of agents 2 to $n$ is increased to the level of the demand of agent 2. We then go to the incremental cost of an intermediate demand in which the demand of agents 3 to $n$ is increased to the level of the demand of agent 3 . This incremental cost is shared equally among agents 3 to $n$ and so on until total demand is satisfied.

The two rules of Sprumont (1998) and Koster et al. (1998) consist in first ordering individual demands according to their stand-alone costs. Next, a first intermediate demand is constructed by reducing demands of agents 2 to $n$ along a ray or an axis down to the point where their stand-alone costs is the same as for agent 1. A second intermediate demand is constructed by reducing demands of agents 3 to $n$ down to the point where their stand-alone costs is the same as for agent 2, etc. Finally, the Moulin-Shenker formula is applied to the costs of these intermediate demands. The rules bear the names Axial or Radial because of the way in which individual demands are reduced to construct intermediate demands.

Rays are particular cases of increasing paths. In some circumstances, it may be natural to adjust all components of the demand of an agent along the ray to which it belongs. In others, this may not be appropriate. For example, it might happen that some of the components should not vary at all or should vary in discontinuous ways while others vary continuously. As pointed out by Koster et al. (1998) in their Remark 3.7, one can envisage other extensions of the Serial Rule using more general paths to scale the demands. This idea leads us to define the Path Serial Rule.

The original Serial Cost Sharing Rule has a simple characterization: it is the only cost sharing rule to satisfy Equal Treatment of Equals (ETE) and Independence of Larger Demands (ILD). (ETE) says that equal demands must be treated identically while (ILD) re- 
quires that the cost share of an agent be independent of the size of the demands that are larger than his or hers. In more general contexts, these conditions do not have much bite since demands are not comparable. Sprumont (1998) proposes stronger forms of these conditions, which he calls respectively Symmetry (S) and the Serial Principle (SP). The idea behind Symmetry is that if the demands of two agents can be interchanged without altering the total cost, then the two goods should be deemed comparable. Then, if the two agents request the same quantity of these two goods, they should be charged the same amount. A stronger property introduced by Koster et al. (1998) is Equal Treatment of Equivalent Demands (ETV), where demands are equivalent when they have the same stand-alone cost.

(ILD) implies the ordering of the agents according to their demands, which may be impossible in more general contexts. Sprumont's answer is to order agents according to the cost shares produced by the rule. Then, the Serial Principle says that an agent who pays less than another agent should not see her cost share change if this other agent increases his demand. Koster et al. (1998) define a weaker form of this property called the Radial Serial Principle (RSP), which says that an agent who pays less than another agent should not see her cost share change if this other agent increases his demand along the ray on which it lays. In the more general context considered here, this property becomes the Path Serial Principle (PSP). Thus, the Axial, the Radial, and the Path Serial Rules are characterized by (ETV) together with (SP), (RSP), and (PSP) respectively.

Moulin and Shenker (1994) show that the original Serial Cost Sharing Rule enjoys other remarkable ethical and coherency properties. Among other results, it is characterized by the combination of Additivity, Separability (for separable cost functions), Free Lunch, and Fair Ranking. Additivity requires that a rule yields the same results, whether it is applied separately to different cost elements or to their sums. Separability says that if cost is a linear function of total demand, then it should be allocated proportionally to the demands. Free Lunch says that if the cost of an $n$-fold replication of an agent's demand is zero, so should be the cost share of this agent. Fair Ranking, also called No-Domination, says that the cost shares of agents should be ordered as their demands. It implies (ETE). Separability, Free Lunch, and Fair Ranking can be transposed to the Path Serial Rule. This is not the case of Additivity. Indeed, Kolpin (1996) shows that there is no extension of the Serial Rule satisfying Scale Invariance and Additivity. Thus, none of the Axial, Radial, and Path Serial Rules satisfies Additivity.

Moulin and Shenker (1994) also prove that, under appropriate assumptions on the cost function, the original Serial Rule produces cost shares that are monotone with respect to own and others' demands and that lay between reasonable bounds. We are able to transpose 
their results to the Path Serial Rule by restricting Monotonicity and Cross Monotonicity to hold along paths.

The original Serial Rule is also immune to arbitrary changes in the way output is measured. It satisfies a property introduced by Sprumont (1998) and called Ordinality, which says that arbitrary changes in the units in which output is measured should not affect cost shares. A weaker property is Scale Invariance, which prescribes the invariance of cost shares with respect to linear changes in the units. We extend Ordinality to the general context considered in this paper by imposing that paths be transformed along the demands and the cost function to give an equivalent problem. The Path Serial Rule satisfies Ordinality thus defined. Actually, this rule amounts to applying the original Serial Rule to a path reduction of the problem at hand.

Coming back to other characterizations, Sprumont (1998) shows that the Axial Serial Rule is the only cost sharing rule that satisfies Symmetry (S), Rank Independence of Irrelevant Agents (RIIA), Independence of Null Agents (INA), Ordinality (O), and the Serial Principle (SP). (RIIA) imposes that the ranking of two agents' cost shares depends on their demands only. Put differently, a change in an agent's demand must not affect the interpersonal ranking of others' cost shares. (INA) states that agents with null demands can be entirely removed from a problem without altering the outcome for the others. This implies that agents with null demands pay zero. This condition is stronger than Dummy.

Koster et al. (1998) assert that Sprumont's characterization of the Axial Serial Rule does not extend to the Radial Serial Rule in their homogeneous context. We reinforce their result by showing that (SP) and (S) are incompatible in this context. Thus (SP) and (ETE) are also incompatible. Since (ETE) is hardly a disputable requirement, (SP) must be weakened in some way. In as much as (PSP) is a sensible way of weakening (SP), the Path Serial Rule is probably the best that we can hope for in the general context. This rule satisfies (S), (RIIA), (INA), and (O) in addition to (PSP). However, we exhibit another rule that satisfies these properties.

\section{The Cost Sharing Problem}

A cost sharing problem starts with a profile of demands, to which a cost function is applied. In some cases, as with serial cost sharing, demands may have to be scaled down to meet certain conditions. The cost sharing problem must thus be completed by a description of how this should be made. We address each of these elements in the next three subsections. Then, we examine special cases of this problem found in the literature and present an example to illustrate the generality of our approach. 


\subsection{The demands}

Throughout this paper, there is a fixed set of divisible commodities $K=\{1, \ldots, k\}$ and a fixed set of agents $N=\{1, \ldots, n\}$. The commodities may be goods, characteristics serving to describe needs, or specifications of a certain facility. A commodity may be specific to a particular agent or a subset of agents. This means that these agents are the only ones to be able to consume, use, or enjoy the commodity in question. Hence, they will be the only ones to demand positive quantities of this commodity. As for non specific commodities, they may be private or public or anything in between.

For each agent $i \in N$, let there be a positive integer $m_{i} \leq k$ and a one-to-one function $\ell_{i}:\left\{1, \ldots, m_{i}\right\} \rightarrow K$, specifying the list of commodities that may be requested by this agent. Next, let $M_{i}$ be the range of $\ell_{i}$, i.e. $M_{i}=\left\{\ell_{i}(1), \ldots, \ell_{i}\left(m_{i}\right)\right\}$. In plain words, $M_{i}$ is the subset of commodities for which agent $i$ may request a positive quantity. We assume that $K=\cup_{i=1}^{n} M_{i}$. Thus, for each commodity, there is at least one agent concerned by this commodity.

The demand of agent $i$ is described by a vector $q_{i} \in \mathbb{R}_{+}^{m_{i}}$. The scalar $q_{i h}$ is the demand of commodity $\ell_{i}(h) \in M_{i}$ by agent $i$. Let $M=\left\{M_{1}, \ldots, M_{n}\right\}$ with cardinality $m=\sum_{i=1}^{n} m_{i} \leq$ $n k$. A profile of demands is an element $Q \in \mathbb{R}_{+}^{m}=\prod_{i=1}^{n} \mathbb{R}_{+}^{m_{i}}$. Given a subset $S \subset N$ and $Q \in \mathbb{R}_{+}^{m}$, let $Q^{S} \in \mathbb{R}_{+}^{m}$ be the vector obtained from $Q$ by changing all components $q_{j}, j \in N \backslash S$, for components of 0 .

\subsection{The cost function}

To complete the description of the problem, we assume that the agents jointly own a facility to jointly produce any list of commodities that are requested. The cost of producing a bundle $Y \in \mathbb{R}_{+}^{m}$ is $C(Y)$. A special case is $M_{i}=K \forall i$ and $C(Y)=c\left(\sum_{i} y_{i}\right)$ with $c$ : $\mathbb{R}_{+}^{k} \rightarrow \mathbb{R}_{+}$. In this case, all commodities are homogeneous and private. Following Moulin and Shenker (1994) and Sprumont (1998), we call these functions and the resulting problems homogeneous.

A cost function $C: \mathbb{R}_{+}^{m} \rightarrow \mathbb{R}_{+}$also induces $n$ stand-alone cost functions $c_{i}: \mathbb{R}_{+}^{m_{i}} \rightarrow \mathbb{R}_{+}$ defined by:

$$
c_{i}\left(y_{i}\right)=C\left(Y^{\{i\}}\right) \forall i \in N
$$

We shall say that $c_{i}: \mathbb{R}_{+}^{m_{i}} \rightarrow \mathbb{R}_{+}$is increasing if $y_{i} \ll y_{i}^{\prime}$ implies $c_{i}\left(y_{i}\right)<c_{i}\left(y_{i}^{\prime}\right)$. Thus, $c_{i}$ is increasing if an increase in all components of $y_{i}$ yields a cost increase.

Let $\mathbb{C}(m)$ be the class of continuous and non-decreasing functions $C: \mathbb{R}_{+}^{m} \rightarrow \mathbb{R}_{+}$satisfying: 
- $C(0)=0$,

- the functions $c_{i}, i=1, \ldots, n$, induced by $C$ are increasing,

- $\forall Y \in \mathbb{R}_{+}^{m}, \forall i \in N: c_{i}\left(y_{i}\right)=0 \Rightarrow C(Y)=C\left(Y^{N \backslash\{i\}}\right)$,

- $\forall i \in N, \forall Y \in \mathbb{R}_{+}^{m}: C\left(Y^{N \backslash\{i\}}\right)=C_{-i}\left(Y_{-i}\right)$, where $C_{-i}$ is the restriction of $C$ to the reduced profile $Y_{-i}=\left(y_{1}, \ldots, y_{i-1}, y_{i+1}, \ldots, y_{n}\right)$

We shall work with this class of functions throughout the paper. Whereas we need the mild assumption that each $c_{i}$ be increasing, we do not want to impose and we do not need that $C$ be increasing. In other words, $Y \leq Y^{\prime} \in \mathbb{R}_{+}^{m}$ and $y_{i} \ll y_{i}^{\prime}$ for some $i$ do not necessarily imply $C(Y)<C\left(Y^{\prime}\right)$. Indeed, $C$ may be the result of a more or less complex aggregation and optimization procedure. Thus, it is not necessarily increasing in all its components as, for example, when some public goods are involved. The two last conditions defining $\mathbb{C}(m)$ are natural. A demand from an agent with null stand-alone cost has the same impact on total cost than a null demand and removing an agent with a null demand from a problem should have no impact on total cost.

A function $C \in \mathbb{C}(m)$ is symmetric in the components $i$ and $j$ if $C(Y)=C\left(Y_{i j}\right) \forall Y \in$ $\mathbb{R}_{+}^{m}$ where $Y_{i j}$ is the vector $Y$ with the components $i$ and $j$ interchanged. This requires that $m_{i}=m_{j}$ but not necessarily $M_{i}=M_{j}$. A function $C \in \mathbb{C}(n k)$ is symmetric if it is symmetric in the components $i$ and $j \forall i, j \in N$. For a symmetric function, we let $m_{i}=k \forall i$. Thus, $m=n k$. A homogeneous function is obviously symmetric.

Note that if $C \in \mathbb{C}(m)$ is symmetric in the components $i$ and $j$, then $c_{i}(x)=c_{j}(x) \forall x \in$ $\mathbb{R}_{+}^{m_{i}}$. Indeed, $c_{i}(x)=C\left(Y^{\{i\}}\right)=C\left(Y^{\{j\}}\right)=c_{j}(x)$ for any $Y \in \mathbb{R}_{+}^{m}$ such that $y_{i}=y_{j}=x$. The middle equality follows from the fact that the difference between $Y^{\{i\}}$ and $Y^{\{j\}}$ amounts to an interchange of the components $i$ and $j$.

In certain circumstances, the shape of the cost function may be of some importance. In particular, the behaviour of the incremental cost, i.e. the change in cost following an increase in the level of production, may matter. These incremental costs may increase or diminish with the level of production. We now give a formal content to these concepts. In the following definition, we treat two increments in two different components of $Y$ as equivalent if their impacts on their respective stand-alone costs are the same. In the case of a single private good, this would imply identical increments. 
Definition 1 A cost function $C \in \mathbb{C}(m)$ satisfies Diminishing Incremental Cost (DIC) if for any triple $\left(Y, Y^{\prime}, Z\right) \in \mathbb{R}_{+}^{3 m}$ such that $Y \leq Y^{\prime}$ and any pair $(i, j) \in N^{2}$ such that $c_{i}\left(y_{i}\right) \geq c_{j}\left(y_{j}\right)$ and $c_{i}\left(y_{i}+z_{i}\right)-c_{i}\left(y_{i}\right)=c_{j}\left(y_{j}+z_{j}\right)-c_{j}\left(y_{j}\right)$, the following holds:

$$
C\left(Y+Z^{\{i\}}\right)-C(Y) \geq C\left(Y^{\prime}+Z^{\{j\}}\right)-C\left(Y^{\prime}\right)
$$

It satisfies Increasing Incremental Cost (IIC) if $-C$ satisfies (DIC).

Remark 1 Why should we insist on (1) to declare $C$ as being a (DIC) function? Note that the condition $c_{i}\left(y_{i}+z_{i}\right)-c_{i}\left(y_{i}\right)=c_{j}\left(y_{j}+z_{j}\right)-c_{j}\left(y_{j}\right)$ may be written as:

$$
C\left(Y^{\{i\}}+Z^{\{i\}}\right)-C\left(Y^{\{i\}}\right)=C\left(Y^{\{j\}}+Z^{\{j\}}\right)-C\left(Y^{\{j\}}\right)
$$

Adding $Y^{\{j\}}$ and $Y^{\{i\}}$ to the arguments of the left and right members respectively should bring a lower value for both. However, the condition $c_{i}\left(y_{i}\right) \geq c_{j}\left(y_{j}\right)$ means that $y_{i}$ is in a sense "larger" than $y_{j}$. Thus $Y^{\{i\}}$ is "larger" than $Y^{\{j\}}$ and if (DIC) holds, we should expect the value of the right member of (2) to decrease more than the left one, i.e. $C\left(Y^{\{i, j\}}+Z^{\{i\}}\right)-$ $C\left(Y^{\{i, j\}}\right) \geq C\left(Y^{\{i, j\}}+Z^{\{j\}}\right)-C\left(Y^{\{i, j\}}\right)$. From this inequality, we may say that $Z^{\{i\}}$ is "larger" than $Z^{\{j\}}$. Thus, we should have $C\left(Y+Z^{\{i\}}\right)-C(Y) \geq C\left(Y+Z^{\{j\}}\right)-C(Y)$. Finally, changing $Y$ for $Y^{\prime}$ in the right member can just reinforce this inequality to meet the claim that $C$ is a (DIC) function. This is precisely what (1) says.

Note that we may have $i=j$. Actually, for homogeneous $C^{2}$ functions, (DIC) is merely an implication of a property of concavity, namely the second order directional derivatives are non-positive. (DIC) has itself several implications, which are recorded in the following lemma.

Lemma 1 Let $C \in \mathbb{C}(m)$ satisfies (DIC), then:

1. For any triple $\left(Y, Y^{\prime}, Z\right) \in \mathbb{R}_{+}^{3 m}$ such that $Y \leq Y^{\prime}$, the following must hold:

$$
C(Y+Z)-C(Y) \geq C\left(Y^{\prime}+Z\right)-C\left(Y^{\prime}\right)
$$

2. For any $Z \in \mathbb{R}_{+}^{m}$, let $I(Z)=\left\{i \in N: z_{i} \neq 0\right\}$. Then, for any triple $\left(Y, Y^{\prime}, Z\right) \in \mathbb{R}_{+}^{3 m}$ such that $Y \leq Y^{\prime}, Y+Z \leq Y^{\prime}+Z^{\{h\}}$ for some $h \in I(Z), c_{i}\left(y_{i}\right) \geq c_{h}\left(y_{h}\right)$ and $c_{i}\left(y_{i}+z_{i}\right)-c_{i}\left(y_{i}\right)=c_{h}\left(y_{h}+z_{h}\right)-c_{h}\left(y_{h}\right) \forall i \in I(Z)$, the following must hold:

$$
C(Y+Z)-C(Y) \geq \# I(Z)\left(C\left(Y^{\prime}+Z^{\{h\}}\right)-C\left(Y^{\prime}\right)\right)
$$


3. For any pair $\left(Y, Y^{\prime}\right) \in \mathbb{R}_{+}^{m} \times \mathbb{R}_{+}^{m}$ such that $Y \leq Y^{\prime}$ we have:

$$
\sum_{i=1}^{n} c_{i}\left(y_{i}^{\prime}\right)-\sum_{i=1}^{n} c_{i}\left(y_{i}\right) \geq C\left(Y^{\prime}\right)-C(Y)
$$

The above propositions hold with the reverse inequality if $C$ satisfies (IIC).

The proof is given in subsection 8.1.

Remark 2 Condition (3) by itself could be viewed as a (DIC) condition. However, while (5) follows from (3), we need the stronger Definition 1 to get (4), which will be needed to prove path cross monotonicity. Since condition (5) can be written as $\sum_{i=1}^{n} c_{i}\left(y_{i}^{\prime}\right)-C\left(Y^{\prime}\right) \geq$ $\sum_{i=1}^{n} c_{i}\left(y_{i}\right)-C(Y)$, it may be called "increasing benefit from cooperation".

\subsection{The paths}

Serial cost sharing requires that larger demands be initially scaled down to a level equivalent to smaller ones. In some circumstances, it may be natural to adjust all components of the demand of an agent along the ray to which it belongs, i.e. proportionally. This is the method used in the Radial Serial Rule. In other circumstances, this may not be appropriate. As pointed out by Koster et al. (1998) in their Remark 3.7, one can envisage other extensions of the serial rule using more general paths to scale the demands. This is the idea developed in this paper. This approach requires that we add the rules according to which demands must be scaled to $Q$ and $C$ in the definition of a cost sharing problem.

For each $i \in N$, consider functions $h_{i}: \mathbb{R}_{+}^{m_{i}+1} \rightarrow \mathbb{R}_{+}^{m_{i}}$, which map each $y \in \mathbb{R}_{+}^{m_{i}}$ and $\tau \in \mathbb{R}_{+}$onto a vector $h_{i}(y, \tau) \in \mathbb{R}_{+}^{m_{i}}$. Assume that $h_{i}(y, \cdot)$ is non-decreasing, increasing in at least one component, and that for each $y \in \mathbb{R}_{+}^{m_{i}}$, there exists a $\tau^{\prime} \in \mathbb{R}_{+}$(necessarily unique) such that $h_{i}\left(y, \tau^{\prime}\right)=y$. Let $\mathcal{H}_{i}$ be the class of these functions. Then, $h_{i}\left(y, \mathbb{R}_{+}\right)$is the path through $y$ defined by $h_{i}(y, \cdot)$. Clearly, the class $\left\{h_{i}\left(y, \mathbb{R}_{+}\right): y \in \mathbb{R}_{+}^{m_{i}}\right\}$ scans $\mathbb{R}_{+}^{m_{i}}$ since $h_{i}$ is defined for each $y \in \mathbb{R}_{+}^{m_{i}}$. Finally, let $h_{i}^{R}: \mathbb{R}_{+}^{m_{i}} \backslash\{0\} \times \mathbb{R}_{+} \rightarrow \mathbb{R}_{+}^{m_{i}}$ be defined by $h_{i}^{R}(y, \tau)=\tau y$. This function defines the ray through a $y \neq 0$.

We do not impose that $h_{i}(y, 0)=0$ and that $h_{i}(y, \cdot)$ be continuous and increasing in all components. However, given a function $C \in \mathbb{C}(m)$, we restrict ourselves to the class of functions $\mathcal{H}_{i}\left(c_{i}\right) \subset \mathcal{H}_{i}$ for which $c_{i}\left(h_{i}(y, \cdot)\right)$ is continuous and increasing, with $c_{i}\left(h_{i}(y, 0)\right)=0$. Since $c_{i}(0)=0$ and since $c_{i}$ is increasing, this implies that there is at least one null component in $h_{i}(y, 0)$. In words, a path starts on an axis but not necessarily at 
the origin. The cost of the bundle at the starting point is null and increasing thereafter. This definition of $\mathcal{H}_{i}\left(c_{i}\right)$ insures that for any $\alpha \in \mathbb{R}_{+}$, there is a unique $\tau_{\alpha}$ such that $c_{i}\left(h_{i}\left(y, \tau_{\alpha}\right)\right)=\alpha$.

Let $\mathcal{H}(C)=\mathcal{H}_{1}\left(c_{1}\right) \times \cdots \times \mathcal{H}_{n}\left(c_{n}\right), H(Y, \tau)=\left(h_{1}\left(y_{1}, \tau_{1}\right), \ldots, h_{n}\left(y_{n}, \tau_{n}\right)\right)$, and $\mathbb{C}(m) \times$ $\mathcal{H}=\{(C, H): C \in \mathbb{C}(m)$ and $H \in \mathcal{H}(C)\}$. A cost sharing problem is a triple $(Q, C, H) \in$ $\mathbb{R}_{+}^{m} \times \mathbb{C}(m) \times \mathcal{H}(C)$. Accordingly, a cost sharing rule is a mapping $\xi: \mathbb{R}_{+}^{m} \times \mathbb{C}(m) \times \mathcal{H} \rightarrow$ $\mathbb{R}_{+}^{n}$ satisfying the budget balance condition:

$$
\sum_{i=1}^{n} \xi_{i}(Q, C, H)=C(Q)
$$

The vector $\xi(Q, C, H)$ is the list of cost shares for the problem $(Q, C, H)$.

The choice of a particular form for $h_{i}$ may be dictated by technical considerations. For example, changing some of the components might not make sense while others may have to vary in discontinuous ways and others continuously. The choice of the paths may also come from the agents themselves, along with their demands. For example, $q_{i}$ is presumably the result of an optimization problem, say:

$$
q_{i}=\arg \max _{y \in Y} U\left(y, c_{i}(y)\right)
$$

where $U$ is a utility or a profit function and $Y \subset \mathbb{R}_{+}^{m_{i}}$. Now, suppose that the agent is restricted to demands that have stand-alone cost $\alpha$, i.e. to the isocost set $I(\alpha)=$ $\left\{y \in Y: c_{i}(y)=\alpha\right\}$. Then, the choice of the agent, if rational, would be:

$$
\gamma(\alpha)=\arg \max _{y \in I(\alpha)} U(y, \alpha)
$$

Under appropriate assumptions on $Y, U$, and $c_{i}, \gamma$ would be a single value and increasing function from $\mathbb{R}_{+}$to $\mathbb{R}_{+}^{m_{i}}$. It would describe a path in $\mathbb{R}_{+}^{m_{i}}$. In particular, one would have $\gamma\left(c_{i}\left(q_{i}\right)\right)=q_{i}$ and $c_{i}(\gamma(\alpha))=\alpha$. We write $h_{i}\left(q_{i}, \alpha\right)$ instead of $\gamma(\alpha)$ to insist on the fact that this path goes trough $q_{i}$. This also means that the same function may describe different paths. Actually, $h_{i}$ may simply be seen as a scaling rule from a given demand. Note that we do not impose the normalisation $c_{i}\left(h_{i}\left(q_{i}, \tau\right)\right)=\tau$.

\subsection{Special cases}

By imposing some restrictions on the sets of commodities, on $C$, or on $H$, we obtain some of the special cases discussed in the literature. For all of them, $h_{i}=h_{i}^{R}$. It defines a ray through $y$ when not an axis or the positive real half-line. Table 1 summarizes their other 
features. Sprumont (1998) takes the commodities as being personalized. With some abuse of notation, we write $M_{i}=\{i\} \forall i$ to describe this case, which implies $M=K=N$. We shall write these special problems as pairs $(Q, C) \in \mathbb{R}_{+}^{m} \times \mathbb{C}(m)$.

\begin{tabular}{|l|l|l|l|}
\hline Moulin-Shenker & $k=1$ & $M_{i}=K \forall i$ & $C(Y)=c\left(\sum_{i} y_{i}\right)$ \\
\hline Koster et al. (1998) & & $M_{i}=K \forall i$ & $C(Y)=c\left(\sum_{i} y_{i}\right)$ \\
\hline Sprumont (1998) & $k=n$ & $M_{i}=\{i\} \forall i$ & \\
\hline
\end{tabular}

Table 1: Special cases

From Table 1, one can see that none of the two problems considered by Sprumont (1998) and Koster et al. (1998) is more general than the other. Koster et al. consider homogeneous problems while for Sprumont, there is only one commodity for each agent. Our problem generalizes both in removing all restrictions on the sets of commodities and on the cost function. Thus, there may be at least one agent $i$ such that $m_{i}>1$. There may also be at least one agent $i$ such that $M_{i} \neq K$. The latter implies that there are at least two agents $i$ and $j$ such that $M_{i} \neq M_{j}$, which in turn implies that the problem is not homogeneous. The problems considered may contain any mix of private, public, and specific commodities. In addition, the $h_{i}$ define paths that are not necessarily rays.

\subsection{An example}

We conclude this section with an example that illustrates the kind of problem that can fit in this general framework. Suppose there are three cities $A, B$ and $C$ that must be supplied with natural gas from point $S$. Thus, a pipeline must be build to link the three cities to the supply $S$. The possible links are represented in Figure 1. Thus, $B$ could be fed directly from $S$ or through $A$.

Let there be two periods, summer and winter. Each city has a demand in each period and this demand is expected to remain the same forever. Thus, the profile of demands is a sextuple:

$$
Q=\left(\left(q_{a s}, q_{a w}\right),\left(q_{b s}, q_{b w}\right),\left(q_{c s}, q_{c w}\right)\right)
$$

Not only is gas in winter different from gas in summer but gas available in one city is different from gas available in a different city. Gas is a specific good. Indeed, supplying additional gas to $A$ has an impact on costs that is different from the impact on costs of supplying the same quantity to $B$ or $C$. 


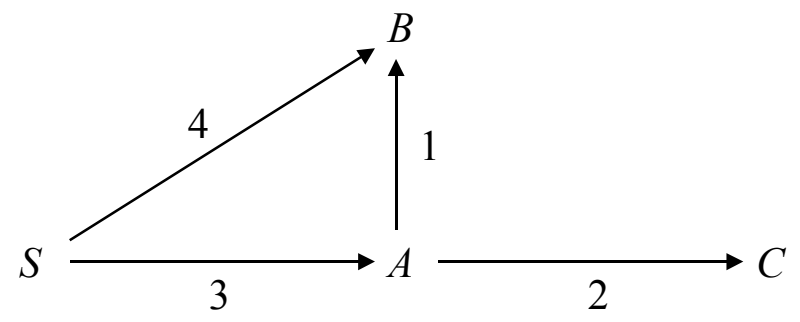

Figure 1: A Network of pipelines

A network of pipelines may be represented by a $\gamma \in \mathbb{R}_{+}^{4}$ specifying the capacity of each of the four segments $A B, A C, S A, S B$. If we assume that the marginal cost of a segment is decreasing with its capacity and if cost is to be minimized, only one of the segments $A B(1)$ and $S B$ (4) will be build. In other words, only two networks are possible: $\gamma_{1}$ with 0 capacity on the last segment and $\gamma_{2}$ with 0 capacity on the first segment. Capacity on each segment of each network depends on the profile of demands. In other words, $\gamma_{1}$ and $\gamma_{2}$ are functions of $Q$. More precisely, $\gamma_{1}: \mathbb{R}_{+}^{6} \rightarrow \mathbb{R}_{+}^{4}$ is defined by:

$$
\gamma_{1}(Q)=\left(\max \left\{q_{b s}, q_{b w}\right\}, \max \left\{q_{c s}, q_{c w}\right\}, \max \left\{q_{a s}+q_{b s}+q_{c s}, q_{a w}+q_{b w}+q_{c w}\right\}, 0\right)
$$

Indeed, the capacities on segments $A B(1)$ and $A C$ (2) must be sufficient to carry the largest quantities required by $B$ and $C$ respectively over the two periods. Moreover, the capacity on segment $S A$ (3) must be sufficient to carry the largest of the total quantity required by the three cities over the two periods. $\gamma_{2}: \mathbb{R}_{+}^{6} \rightarrow \mathbb{R}_{+}^{4}$ is defined in a similar way.

$$
\gamma_{2}(Q)=\left(0, \max \left\{q_{c s}, q_{c w}\right\}, \max \left\{q_{b s}+q_{c s}, q_{b w}+q_{c w}\right\}, \max \left\{q_{b s}, q_{b w}\right\}\right)
$$

Suppose that the cost of building a network $\gamma$ is given by a function $c: \mathbb{R}_{+}^{4} \rightarrow \mathbb{R}_{+}$. Then, $C$ would be given by:

$$
C(Q)=\min \left\{c\left(\gamma_{1}(Q)\right), c\left(\gamma_{2}(Q)\right)\right\}
$$

No need to say, thus far this problem does not fit the frameworks considered by Sprumont or Koster et al. (1998). In addition, customers in each city may want that, if needed, the demand be scaled in a non proportional way. For example, they may ask that if scaling down is needed, the largest demand be first reduced until it reaches the size of the smallest demand and that both demands be then reduced proportionally. Scaling up in a proportional way 
would be acceptable. The prescribed path is described by the following function $h_{i}: \mathbb{R}_{+}^{3} \rightarrow$ $\mathbb{R}_{+}^{2}$ :

$$
h_{i}(y, \tau)=\left\{\begin{array}{lll}
\left(\min \left\{\max \left\{\tau y_{s}, y_{s}\right\}, \tau y_{w}\right\}, \tau y_{w}\right) & \text { if } y_{s} \leq y_{w} \\
\left(\tau y_{s}, \min \left\{\max \left\{\tau y_{w}, y_{w}\right\}, \tau y_{s}\right\}\right) & \text { if } y_{s}>y_{w}
\end{array}\right.
$$

This function belongs to $\mathcal{H}_{i}$. One can insure that it belongs to $\mathcal{H}_{i}\left(c_{i}\right)$ by imposing that $c_{i}$ be increasing, be it slightly, with respect to both $y_{i s}$ and $y_{i w}$.

\section{The Path Serial Cost Sharing Rule}

The original version of the Serial Cost Sharing Rule has been introduced by Shenker (1990) and characterized by Moulin and Shenker $(1992,1994)$ in the context where the individuals request a single private good, i.e. $k=1$ and $C(Q)=c\left(\sum_{i} q_{i}\right)$. Before presenting an extension of this rule to the general context considered here, we give the definition of the Direct Serial Rule introduced by Sprumont (1998). This is simply the Moulin-Shenker rule applied to a problem $(Q, C) \in \mathbb{R}_{+}^{n} \times \mathbb{C}(n)$ that is not necessarily homogeneous. This direct rule will prove useful in assessing the properties of the Path Serial Cost Sharing Rule.

Definition 2 (The Direct Serial Rule) Consider a problem $(Q, C) \in \mathbb{R}_{+}^{n} \times \mathbb{C}(n)$ where $Q$ is naturally ordered, i.e. $q_{1} \leq \ldots \leq q_{n}$. Then, consider the intermediate request vectors $Q^{i}=\left(q_{1}^{i}, \ldots, q_{n}^{i}\right) \in \mathbb{R}_{+}^{n}, i=1, \ldots, n$, defined by $q_{j}^{i}=\min \left\{q_{i}, q_{j}\right\} \forall j \in N$. The Direct Serial Rule $\xi^{D S}: \mathbb{R}_{+}^{n} \times \mathbb{C}(n) \rightarrow \mathbb{R}_{+}^{n}$ is defined by:

$$
\xi_{i}^{D S}(Q, C)=\sum_{j=1}^{i} \frac{C\left(Q^{j}\right)-C\left(Q^{j-1}\right)}{n+1-j}, i=1, \ldots, n
$$

In the context of Moulin and Shenker, $C\left(Q^{1}\right)=c\left(n q_{1}\right), C\left(Q^{2}\right)=c\left(q_{1}+(n-1) q_{2}\right)$, $C\left(Q^{3}\right)=c\left(q_{1}+q_{2}+(n-2) q_{3}\right)$, and so on. Thus all agents share equally the cost $c\left(n q_{1}\right)$ of a list of identical demands $\left(q_{1}, \ldots, q_{1}\right)$. Then, agents $2, \ldots, n$ shares equally $c\left(q_{1}+(n-1) q_{2}\right)-$ $c\left(n q_{1}\right)$, i.e. the cost increase when the demand is changed from $\left(q_{1}, \ldots, q_{1}\right)$ to $\left(q_{1}, q_{2}, \ldots, q_{2}\right)$, and so on. Note that in this context, $q_{1} \leq \ldots \leq q_{n}$ is equivalent to $c_{1}\left(q_{1}\right) \leq c_{2}\left(q_{2}\right) \leq \ldots \leq$ $c_{n}\left(q_{n}\right)$. This is not so for a more general problem $(Q, C) \in \mathbb{R}_{+}^{n} \times \mathbb{C}(n)$ since different agents may request different commodities. Actually, the order between agents may depend on the units in which these demands are expressed and thus, the cost shares may depend on this choice. This is certainly something that we want to avoid. In addition, with heterogeneous commodities, $\left(q_{1}, \ldots, q_{1}\right)$ is not necessarily a vector of identical demands. Thus, there is no 
point in defining intermediate demands in this way. Moreover, this would not work in the general context where the number of commodities may be different from one $M_{i}$ to the other.

The Path Serial Rule that we now define takes care of these particularities. In essence, it consists in first ordering individual demands according to their stand-alone costs. Next, a first intermediate demand is constructed by reducing demands of agents 2 to $n$ along the respective paths specified by the $h_{i}$, down to the points where their stand-alone costs are the same as for agent 1. A second intermediate demand is constructed by reducing demands of agents 3 to $n$ along the same paths down to the point where their stand-alone costs are the same as for agent 2, etc. Finally, the formula of the direct serial rule is applied to the costs of these intermediate demands.

Definition 3 (The Path Serial Rule) Given a problem $(Q, C, H) \in \mathbb{R}_{+}^{m} \times \mathbb{C}(m) \times \mathcal{H}(C)$, suppose, without loss of generality, that agents are ranked according to their $c_{i}\left(q_{i}\right)$ :

$$
c_{1}\left(q_{1}\right) \leq c_{2}\left(q_{2}\right) \leq \ldots \leq c_{n}\left(q_{n}\right)
$$

Then, for each $i$, consider the intermediate demand $Q^{i}=\left(q_{1}^{i}, \ldots, q_{n}^{i}\right) \in \mathbb{R}_{+}^{m}$ defined by:

$$
\begin{cases}q_{j}^{i}=q_{j} & \text { if } \quad c_{j}\left(q_{j}\right) \leq c_{i}\left(q_{i}\right) \\ q_{j}^{i} \in h_{j}\left(q_{j}, \mathbb{R}_{+}\right) \text {and } c_{j}\left(q_{j}^{i}\right)=c_{i}\left(q_{i}\right) & \text { if } \quad c_{j}\left(q_{j}\right)>c_{i}\left(q_{i}\right)\end{cases}
$$

By definition of $\mathcal{H}(C)$, these intermediate demands are uniquely defined. Finally, the cost allocation of the Path Serial Rule is given by the following formula:

$$
\xi_{i}^{P S}(Q, C, H)=\sum_{j=1}^{i} \frac{C\left(Q^{j}\right)-C\left(Q^{j-1}\right)}{n+1-j}, i=1, \ldots, n .
$$

Remark 3 The Radial Serial Rule $\xi^{R S}$ of Koster et al. (1998) may be seen as the Path Serial Rule $\xi^{P S}$ with the use of $h_{i}^{R}$ as the scaling function for all $i$, and any pair $(Q, C) \in \mathbb{R}_{+}^{m} \times \mathbb{C}(m)$. In short, $\xi^{R S}(Q, C)=\xi^{P S}\left(Q, C, H^{R}\right)$. Both $\xi^{P S}$ and $\xi^{R S}$ reduce to the Axial Rule $\xi^{A}$ of Sprumont (1998) when $M_{i}=\{i\} \forall i$ and all three reduce to the Moulin-Shenker rule in the context of the single private good. We say that they are Serial Extensions of the original Serial Rule.

Moulin and Shenker $(1992,1994)$ show that the Serial Rule, i.e. $\xi^{D S}$, has interesting ethical and consistency properties in the context of the single private good. Can we say as much of the Path Serial Rule $\xi^{P S}$ ? More generally, does there exist a serial extension that possesses the same or similar interesting properties? Before addressing this question, 
we associate to any problem $(Q, C, H) \in \mathbb{R}_{+}^{m} \times \mathbb{C}(m) \times \mathcal{H}(C)$, a reduced problem of a particular interest in the following way. Let $c_{h_{i} y}^{-1}: \mathbb{R}_{+} \rightarrow \mathbb{R}_{+}^{m_{i}}, i=1, \ldots, n$, be defined by

$$
c_{h_{i} y}^{-1}(\alpha)=h_{i}(y, \tau): c_{i}\left(h_{i}(y, \tau)\right)=\alpha
$$

and $c_{Q}^{H}: \mathbb{R}_{+}^{n} \rightarrow \mathbb{R}_{+}$be defined by:

$$
c_{Q}^{H}(x)=C\left(c_{h_{1} q_{1}}^{-1}\left(x_{1}\right), \ldots, c_{h_{n} q_{n}}^{-1}\left(x_{n}\right)\right)
$$

Finally, write $\breve{c}(Q)=\left(c_{1}\left(q_{1}\right), \ldots, c_{n}\left(q_{n}\right)\right)$. For a problem $(Q, C) \in \mathbb{R}_{+}^{n} \times \mathbb{C}(n)$, the function $c_{h_{i} y}^{-1}$ is simply the inverse $c_{i}^{-1}$. In this case, we have $\left(\breve{c}(Q), c_{Q}^{H}\right)=\left(q^{A}, c^{A}\right)$ where the latter is the normalized problem of Sprumont (1998).

Definition 4 A problem $(Q, C) \in \mathbb{R}_{+}^{n} \times \mathbb{C}(n)$ is said normalized if $\left(\breve{c}(Q), c_{Q}^{H}\right)=(Q, C)$. In particular, the problem $\left(\breve{c}(Q), c_{Q}^{H}\right) \in \mathbb{R}_{+}^{n} \times \mathbb{C}(n)$ defined by (6-7) is normalized. We call it the normalized path reduction of $(Q, C, H)$.

We now state, without proof, a very important lemma.

Lemma 2 The Path Serial Rule $\xi^{P S}$ is given by:

$$
\xi^{P S}(Q, C, H)=\xi^{D S}\left(\breve{c}(Q), c_{Q}^{H}\right)
$$

i.e. by applying the Direct Serial Rule to the normalized path reduction of the problem $(Q, C, H)$.

The last lemma says that $\xi^{P S}$ consists in applying $\xi^{D S}$ to a problem in which each vector of demands is replaced by its stand alone cost as with $\xi^{A}$. However, there is more to it than just a transformation of vectors of quantities into a scalar. The definition of the cost function that applies to the reduced demands involves a projection of each demand onto a manifold of dimension one, i.e. a path.

Not surprisingly, there is a cost associated with this reduction, even in the homogeneous case. As we shall see, $\xi^{P S}$ does not satisfy all of the properties that $\xi^{D S}$ meets in the single specific good context of Sprumont or the single private good context of Moulin-Shenker. However, since $\xi^{P S}$ is tantamount to applying the Axial Rule to the normalized path reduction of the problem, it satisfies a restriction of some of these properties to the paths along which the rules operates. This idea is developed somewhat more formally in the next remark.

Remark 4 Take any property (A) that says how a cost sharing rule should behave as a result of a change say $\Delta Q$ in the demand $Q$. It may not be satisfied in the general context 
by a given rule $\xi$. However, given a problem $(Q, C, H) \in \mathbb{R}_{+}^{m} \times \mathbb{C}(m) \times \mathcal{H}(C)$, consider the weakening of $(\mathrm{A})$ to which we give the name $(\mathrm{PA})$ and which is obtained by requiring the predicate of (A) to hold only for changes $\Delta q_{i}$ taking place along the path $h_{i}\left(q_{i}, \mathbb{R}_{+}\right)$. Clearly, if a rule $\xi$ is defined by applying some other rule $\xi^{N}$ to the reduced problem $\left(\breve{c}(Q), c_{Q}^{H}\right)$, i.e. if $\xi(Q, C, H)=\xi^{N}\left(\breve{c}(Q), c_{Q}^{H}\right)$, then $\xi$ satisfies (PA) whenever $\xi^{N}$ satisfies (A) on the class of normalized problems of $\mathbb{R}_{+}^{n} \times \mathbb{C}(n)$. Conversely, if $\xi$ satisfies (PA), then $\xi^{N}$ satisfies (A) on the class of normalized problems of $\mathbb{R}_{+}^{n} \times \mathbb{C}(n)$. Indeed, $\xi$ may be applied to a normalized problem $(Q, C) \in \mathbb{R}_{+}^{n} \times \mathbb{C}(n)$. For such a problem, $\left(\breve{c}(Q), c_{Q}^{H}\right)=(Q, C)$, hence $\xi(Q, C)=\xi^{N}(Q, C)$. Moreover, in $\mathbb{R}_{+}^{n} \times \mathbb{C}(n),(\mathrm{PA})$ reduces to (A).

\section{$5 \quad$ Properties of Cost Sharing Rules}

We expect a cost sharing rule to produce coherent results and to obey some equity criteria. The first subsection deals with the requirement that cost shares be independent of the units in which demands are expressed. The other subsections present and relate equity criteria.

\section{$5.1 \quad$ Ordinality}

Almost everybody would agree with the requirement that final cost shares should not depend on the units in which demands are measured. In the literature on cost sharing and game theory, one often finds a condition called Scale Invariance (SI), which says that linear but otherwise arbitrary and independent rescalings of the units should not affect final cost shares. Sprumont (1998) argues that no rescaling of the units should affect the cost shares, not only linear ones. He calls a rule that satisfies this requirement ordinal. We transpose his definition to the general context of this paper. This requires transforming the scaling functions $h_{i}$ in addition to the units and the cost function.

Let $\mathcal{F}(m)$ be the class of separable, increasing and one-to-one correspondences $f: \mathbb{R}_{+}^{m} \rightarrow$ $\mathbb{R}_{+}^{m}$. More precisely, each $f \in \mathcal{F}(m)$ is a list of $m$ increasing one-to-one correspondences $f_{i \ell}$ : $\mathbb{R}_{+} \rightarrow \mathbb{R}_{+}, \ell=\ell_{i}(1), \ldots, \ell_{i}\left(m_{i}\right) ; i=1, \ldots, n$. Let $f(Y)=\left(f_{1}\left(y_{1}\right), \ldots, f_{n}\left(y_{n}\right)\right) \forall Y \in \mathbb{R}_{+}^{m}$. We define two problems $(Q, C, H) \in \mathbb{R}_{+}^{m} \times \mathbb{C}(m) \times \mathcal{H}(C)$ and $\left(Q^{\prime}, C^{\prime}, H^{\prime}\right) \in \mathbb{R}_{+}^{m} \times \mathbb{C}(m) \times$ $\mathcal{H}\left(C^{\prime}\right)$ as ordinally equivalent if there exists a transformation $f \in \mathcal{F}(m)$ such that:

- $Q=f\left(Q^{\prime}\right)$,

- $h_{i}\left(q_{i}, \mathbb{R}_{+}\right)=f_{i}\left(h_{i}^{\prime}\left(q_{i}^{\prime}, \mathbb{R}_{+}\right)\right)$or equivalently $h_{i}\left(f_{i}\left(q_{i}^{\prime}\right), \mathbb{R}_{+}\right)=f_{i}\left(h_{i}^{\prime}\left(q_{i}^{\prime}, \mathbb{R}_{+}\right)\right) \forall i \in N$,

- $C^{\prime}(Y)=C(f(Y)) \forall Y \in \mathbb{R}_{+}^{m}$. 
Under this definition, the demand of each commodity by each agent may be transformed by any increasing function. This function may be different from one commodity to the other and from one agent to the other. However, separability requires that the transformation of each unit be done independently from the demand for the other commodities. The path $h_{i}^{\prime}\left(q_{i}^{\prime}, \mathbb{R}_{+}\right)$is also transformed into the path $h_{i}\left(q_{i}, \mathbb{R}_{+}\right)$and the cost function $C$ into $C^{\prime}$ along the transformation of $q_{i}^{\prime}$ into $q_{i}$.

Definition 5 A cost sharing rule $\xi: \mathbb{R}_{+}^{m} \times \mathbb{C}(m) \times \mathcal{H} \rightarrow \mathbb{R}_{+}^{n}$ satisfies Ordinality (O) if for any pair of ordinally equivalent problems $(Q, C, H) \in \mathbb{R}_{+}^{m} \times \mathbb{C}(m) \times \mathcal{H}(C)$ and $\left(Q^{\prime}, C^{\prime}, H^{\prime}\right) \in$ $\mathbb{R}_{+}^{m} \times \mathbb{C}(m) \times \mathcal{H}\left(C^{\prime}\right)$, we have $\xi(Q, C, H)=\xi\left(Q^{\prime}, C^{\prime}, H^{\prime}\right)$.

We now give an example of two ordinally equivalent problems. Consider a problem $(Q, C, H) \in \mathbb{R}_{+}^{4} \times \mathbb{C}(4) \times \mathcal{H}(C)$ with $q_{1}=(1,1), q_{2}=(1,4)$,

$$
C(Y)=\left(y_{11}+y_{12}+y_{21}+y_{22}\right)
$$

and $h_{i}=h_{i}^{R}$ for $i=1,2$. Next, let $f_{1}: \mathbb{R}_{+}^{2} \rightarrow \mathbb{R}_{+}^{2}$ be defined by $f_{2}\left(y_{1}, y_{2}\right)=\left(y_{1}, y_{2}\right)$ and $f_{2}: \mathbb{R}_{+}^{2} \rightarrow \mathbb{R}_{+}^{2}$ by $f_{2}\left(y_{1}, y_{2}\right)=\left(y_{1}, y_{2}^{2}\right)$. We obtain an equivalent problem $\left(Q^{\prime}, C^{\prime}, H^{\prime}\right) \in$ $\mathbb{R}_{+}^{4} \times \mathbb{C}(4) \times \mathcal{H}(C)$ by defining:

$$
\begin{gathered}
q_{1}^{\prime}=f_{1}^{-1}\left(q_{1}\right)=(1,1) ; \quad q_{2}^{\prime}=f_{2}^{-1}\left(q_{2}\right)=(1,2) \\
C^{\prime}(Y)=C(f(Y))=y_{11}+y_{12}+y_{21}+y_{22}^{2}
\end{gathered}
$$

$H^{\prime}$ must meet the condition $h_{i}\left(f_{i}\left(q_{i}^{\prime}\right), \mathbb{R}_{+}\right)=f_{i}\left(h_{i}^{\prime}\left(q_{i}^{\prime}, \mathbb{R}_{+}\right)\right)$or equivalently $h_{i}^{\prime}\left(q_{i}^{\prime}, \mathbb{R}_{+}\right)=$ $f_{i}^{-1}\left(h_{i}\left(f_{i}\left(q_{i}^{\prime}\right), \mathbb{R}_{+}\right)\right), i=1,2$. Accordingly, we set

$$
h_{i}^{\prime}(y, \tau)=f_{i}^{-1}\left(h_{i}\left(f_{i}(y), \tau\right)\right) \quad \forall \tau \in \mathbb{R}_{+}, i=1,2
$$

Substituting the definitions of $f_{i}$ and $h_{i}$ in the preceding identity, we get $h_{1}^{\prime}=h_{1}$ and:

$$
h_{2}^{\prime}(y, \tau)=h_{2}\left(\tau y_{1}, \sqrt{\tau} y_{2}\right) \quad \forall \tau \in \mathbb{R}_{+}
$$

While $h_{2}$ defines rays, this is not the case of $h_{2}^{\prime}$.

Remark 5 If $f$ is linear, then $(\mathrm{O})$ reduces to the standard Scale Invariance. In particular, $f$ transforms rays into rays. The above example shows that this is not necessarily the case with an arbitrary $f \in \mathcal{F}(m)$. Consequently, the Radial Cost Sharing rule does not satisfy (O) since this rule operates along rays. Put differently, the requirement that rays be transformed into rays places some restriction on the class of admissible transformation functions. This restriction led Koster et al. (1998) to define a weaker invariance condition that they name Radial Ordinality. 
Interestingly, two ordinally equivalent problems have the same path reduction. Thus a cost sharing rule that is defined on the path reduction of a problem satisfies $(\mathrm{O})$.

Lemma 3 Given a pair of ordinal equivalent problems $(Q, C, H) \in \mathbb{R}_{+}^{m} \times \mathbb{C}(m) \times \mathcal{H}(C)$ and $\left(Q^{\prime}, C^{\prime}, H^{\prime}\right) \in \mathbb{R}_{+}^{m} \times \mathbb{C}(m) \times \mathcal{H}\left(C^{\prime}\right)$, we have $\left(\breve{c}(Q), c_{Q}^{H}\right)=\left(\breve{c}\left(Q^{\prime}\right), c_{Q^{\prime}}^{H^{\prime}}\right)$.

The proof is given in subsection 8.2. Combining Lemmas 2 and 3, we obtain the following corollary.

Corollary 4 The Path Serial Rule $\xi^{P S}$ satisfies (O).

\subsection{Equal Treatment of Equivalents}

The two essential features of the Serial Cost Sharing Rule introduced by Moulin and Shenker (1992) is the equal treatment of equal demands and the protection it offers to agents with small requests against larger ones. In the general context of this paper, requests are not necessarily comparable in terms of quantities. Sprumont (1998) and Koster et al. (1998) address this problem and propose reinforcements of the properties just mentioned. In this subsection, we review the definitions relating to the equal treatment of equal requests. The protection against larger requests follows in the next subsection. We start with a property called Fair Ranking or No-Domination, which implies equal treatment of equal requests for homogeneous problems.

Definition 6 A cost sharing rule $\xi: \mathbb{R}_{+}^{m} \times \mathbb{C}(m) \times \mathcal{H} \rightarrow \mathbb{R}_{+}^{n}$ satisfies Fair Ranking (FR) if for any homogeneous problem $(Q, C, H) \in \mathbb{R}_{+}^{n k} \times \mathbb{C}(n k) \times \mathcal{H}(C)$ and $i, j \in N$, the following holds:

$$
q_{i} \leq q_{j} \Rightarrow \xi_{i}(Q, C, H) \leq \xi_{j}(Q, C, H)
$$

Definition 7 A cost sharing rule $\xi: \mathbb{R}_{+}^{m} \times \mathbb{C}(m) \rightarrow \mathbb{R}_{+}^{n}$ satisfies Equal Treatment of Equals (ETE) if for any homogeneous problem $(Q, C, H) \in R_{+}^{n k} \times C(n k) \times \mathcal{H}(C)$ and $i, j \in N$, the following holds:

$$
q_{i}=q_{j} \Rightarrow \xi_{i}(Q, C, H)=\xi_{j}(Q, C, H)
$$

Koster et al. (1998) introduce a stronger condition, based on the notion of equivalent requests. A very natural criterion to order two individual requests is their stand-alone cost. Thus, $q_{i}$ and $q_{j}$ are equivalent if $c_{i}\left(q_{i}\right)=c_{j}\left(q_{j}\right)$. This criterion yields the following reinforcement of the above two properties. 
Definition 8 A cost sharing rule $\xi: \mathbb{R}_{+}^{m} \times \mathbb{C}(m) \times \mathcal{H} \rightarrow \mathbb{R}_{+}^{n}$ satisfies Fair Ranking with respect to stand-alone cost (FRV) if for all $(Q, C, H) \in \mathbb{R}_{+}^{m} \times \mathbb{C}(m) \times \mathcal{H}(C)$ and $i, j \in N$, the following holds:

$$
c_{i}\left(q_{i}\right) \leq c_{j}\left(q_{j}\right) \Rightarrow \xi_{i}(Q, C, H) \leq \xi_{j}(Q, C, H)
$$

Definition 9 A cost sharing rule $\xi: \mathbb{R}_{+}^{m} \times \mathbb{C}(m) \times \mathcal{H} \rightarrow \mathbb{R}_{+}^{n}$ satisfies Equal Treatment of Equivalents (ETV) if for all $(Q, C, H) \in \mathbb{R}_{+}^{m} \times \mathbb{C}(m) \times \mathcal{H}(C)$ and $i, j \in N$, the following holds:

$$
c_{i}\left(q_{i}\right)=c_{j}\left(q_{j}\right) \Rightarrow \xi_{i}(Q, C, H)=\xi_{j}(Q, C, H)
$$

Sprumont (1998) uses the property of Symmetry instead, which can also be extended to the general context. Comparing the requests of two different agents does not in general make sense. It does make sense however if the two lists of commodities requested by the two agents are sufficiently similar. One circumstance in which the commodities requested by agent $i$ can be declared similar to those requested by agent $j$ is when the cost function is symmetric in the components $i$ and $j$, i.e. $C(Y)=C\left(Y_{i j}\right) \forall Y \in \mathbb{R}_{+}^{m}$.

Definition 10 A cost sharing rule $\xi: \mathbb{R}_{+}^{m} \times \mathbb{C}(m) \times \mathcal{H} \rightarrow \mathbb{R}_{+}^{n}$ satisfies Symmetry (S) if for all $(Q, C, H) \in \mathbb{R}_{+}^{m} \times \mathbb{C}(m) \times \mathcal{H}(C)$ and $i, j \in N$ such that $C$ is symmetric in the components $i$ and $j$, the following holds:

$$
q_{i}=q_{j} \Rightarrow \xi_{i}(Q, C, H)=\xi_{j}(Q, C, H)
$$

Remark 6 (ETV) implies (S), which implies (ETE). The converse is not true in general. (ETE) does not imply (S) since a cost function may be symmetric without being homogeneous. Only for homogeneous problems are (S) and (ETE) identical. (S) does not imply (ETV) since we can have $c_{i}\left(q_{i}\right)=c_{i}\left(q_{j}\right)$ without having $q_{i}=q_{j}$.

Remark 7 The fact that $\xi^{D S}$ satisfies (FR) on the class of normalized problems implies that $\xi^{P S}$ satisfies (FRV). More generally, let a rule $\xi: \mathbb{R}_{+}^{m} \times \mathbb{C}(m) \times \mathcal{H} \rightarrow \mathbb{R}_{+}^{n}$ be defined from a rule $\xi^{N}: \mathbb{R}_{+}^{n} \times \mathbb{C}(n) \rightarrow \mathbb{R}_{+}^{n}$ by $\xi(Q, C, H)=\xi^{N}\left(\breve{c}(Q), c_{Q}^{H}\right)$. Then, $\xi$ satisfies (FRV) if and only $\xi^{N}$ satisfies (FR) on the class of normalized problems. As a corollary, $\xi$ satisfies (ETV) if and only if $\xi^{N}$ satisfies (ETE) on the class of normalized problems.

\subsection{The Serial Principle}

This subsection is devoted to the protection of agents with small demands with respect to larger demands. The original condition has been defined for the single private good case. 
We first extend the definition to the general context. However, this condition does not have much bite in this context since demands are not necessarily comparable. Sprumont (1998) proposes a more powerful condition called the Serial Principle. We show that the latter is incompatible with Equal Treatment of Equals. This leads us to weaken the Serial Principle into the Path Serial Principle. The subsection ends with two related conditions called Rank Independence of Irrelevant Agents and Independence of Null Agents.

Definition 11 A cost sharing rule $\xi: \mathbb{R}_{+}^{m} \times \mathbb{C}(m) \times \mathcal{H} \rightarrow \mathbb{R}_{+}^{n}$ satisfies Independence of Larger Demands (ILD) if for two cost sharing problems $(Q, C, H)$ and $\left(Q^{\prime}, C, H^{\prime}\right) \in \mathbb{R}_{+}^{n k} \times$ $\mathbb{C}(n k) \times \mathcal{H}(C)$ such that $M_{i}=K \forall i$ and any $i \in N$ such that $q_{i}^{\prime}=q_{i}$ and

$$
\begin{aligned}
& q_{j}^{\prime}=q_{j} \quad \forall j \in N \backslash\{i\}: q_{j}<q_{i} \\
& q_{j}^{\prime} \geq q_{j} \quad \forall j \in N \backslash\{i\}: q_{i} \leq q_{j}
\end{aligned}
$$

the following holds:

$$
\xi_{i}(Q, C, H)=\xi_{i}\left(Q^{\prime}, C, H^{\prime}\right)
$$

In the general context, (ILD) has no real content since demands cannot be compared. In the homogeneous case, things are better but the condition remains weak since the relation $\leq$ on $\mathbb{R}^{k}$ is not complete. Not all demands can be compared. To obviate these problems, Sprumont (1998) proposes that the demands be ordered according to the cost shares produced by the cost sharing rule itself. This yields the Serial Principle, which requires that an agent's cost share be unaffected by increases in the demands of those who initially pay more than him.

Definition 12 A cost sharing rule $\xi: \mathbb{R}_{+}^{m} \times \mathbb{C}(m) \times \mathcal{H} \rightarrow \mathbb{R}_{+}^{n}$ satisfies the Serial Principle (SP) if for two cost sharing problems $(Q, C, H)$ and $\left(Q^{\prime}, C, H^{\prime}\right) \in \mathbb{R}_{+}^{m} \times \mathbb{C}(m) \times \mathcal{H}(C)$, and any $i \in N$ such that $q_{i}^{\prime}=q_{i}$ and

$$
\begin{array}{ll}
q_{j}^{\prime}=q_{j} & \forall j \in N \backslash\{i\}: \xi_{j}(Q, C, H)<\xi_{i}(Q, C, H) \\
q_{j}^{\prime} \geq q_{j} & \forall j \in N \backslash\{i\}: \xi_{i}(Q, C, H) \leq \xi_{j}(Q, C, H)
\end{array}
$$

the following holds:

$$
\xi_{i}(Q, C, H)=\xi_{i}\left(Q^{\prime}, C, H^{\prime}\right)
$$

In the general context of this paper, $(\mathrm{SP})$ is a very demanding condition. It is not necessarily satisfied by a serial extension. Actually, it is incompatible with (ETE), hence with (ETV), which is a basic property of the Path Serial Rule. 
Theorem 5 If $m_{i} \geq 2$ for at least one $i$, there does not exist a cost sharing rule that satisfies (ETE) and (SP).

The proof is given in subsection 8.3. Since (ETE) is a hardly disputable equity condition, the only avenue left is to weaken the Serial Principle (SP) into a less demanding condition. In line with Remark 4, we consider a restriction of (SP) to paths. In the original definitions of (ILD) and (PS), $H$ plays no role. Hence, we require that their extensions to the general context hold whether $H$ is changed along with $Q$ or not. This is different in the next definition as we require that $q_{j} \in h_{j}\left(q_{j}^{\prime}, \mathbb{R}_{+}\right)$.

Definition 13 A cost sharing rule $\xi: \mathbb{R}_{+}^{m} \times \mathbb{C}(m) \times \mathcal{H} \rightarrow \mathbb{R}_{+}^{n}$ satisfies the Path Serial Principle (PSP) if for any two cost sharing problems $(Q, C, H)$ and $\left(Q^{\prime}, C, H\right) \in \mathbb{R}_{+}^{m} \times$ $\mathbb{C}(m) \times \mathcal{H}(C)$, any $i \in N$ such that $q_{i}^{\prime}=q_{i}$ and

$$
\begin{array}{ll}
q_{j}^{\prime}=q_{j} & \forall j \in N \backslash\{i\}: \xi_{j}(Q, C, H)<\xi_{i}(Q, C, H) \\
q_{j} \in h_{j}\left(q_{j}^{\prime}, \mathbb{R}_{+}\right) \text {and } q_{j}^{\prime} \geq q_{j} & \forall j \in N \backslash\{i\}: \xi_{i}(Q, C, H) \leq \xi_{j}(Q, C, H)
\end{array}
$$

the following holds:

$$
\xi_{i}(Q, C, H)=\xi_{i}\left(Q^{\prime}, C, H\right)
$$

Remark 8 Since $\xi^{D S}$ satisfies (SP) in $\mathbb{R}_{+}^{n} \times \mathbb{C}(n)$, applying the same reasoning as in Remark 4 yields: $\xi^{P S}$ satisfies (PSP). Actually, the fact that $\xi^{D S}$ satisfies (ILD) on the class of normalized problems in $\mathbb{R}_{+}^{n} \times \mathbb{C}(n)$ yields the same conclusion.

We conclude this section by transposing to the general context two properties introduced by Sprumont (1998). The first imposes on a cost sharing rule that the ranking of two agents' cost shares depends on their demands only. Thus, a change in an agent's demand must not affect the interpersonal ranking of the other cost shares. The second says that an agent with a null stand-alone cost can be entirely removed from any problem without altering the outcome for the other agents. This implies of course that agents with null demands pay zero. Both are satisfied by the Path Serial Rule.

Definition 14 A cost sharing rule $\xi: \mathbb{R}_{+}^{m} \times \mathbb{C}(m) \times \mathcal{H} \rightarrow \mathbb{R}_{+}^{n}$ satisfies Rank Independence of Irrelevant Agents (RIIA) if for two cost sharing problems $(Q, C, H)$ and $\left(Q^{\prime}, C, H\right) \in$ $\mathbb{R}_{+}^{m} \times \mathbb{C}(m) \times \mathcal{H}(C)$ such that $q_{i}=q_{i}^{\prime}$ and $q_{j}=q_{j}^{\prime}$ for some $i, j \in N$, then:

$$
\xi_{i}(Q, C, H) \leq \xi_{j}(Q, C, H) \Leftrightarrow \xi_{i}\left(Q^{\prime}, C, H^{\prime}\right) \leq \xi_{j}\left(Q^{\prime}, C, H^{\prime}\right)
$$


Definition 15 Given a profile $Q \in \mathbb{R}_{+}^{m}$, let $\xi^{N \backslash\{i\}}$ be the restriction of $\xi$ to the reduce profile $Q_{-i}=\left(q_{1}, \ldots, q_{i-1}, q_{i+1}, \ldots, q_{n}\right)$ and $C_{-i}$ and $H_{-i}$ be the restrictions of $C$ and $H$ respectively to $Q_{-i}$. A cost sharing rule $\xi: \mathbb{R}_{+}^{m} \rightarrow \mathbb{R}_{+}^{n} \times \mathcal{H}$ satisfies Independence of Null Agents (INA) if for any $(Q, C, H) \in \mathbb{R}_{+}^{m} \times \mathbb{C}(m) \times \mathcal{H}(C)$ and any $i \in N$, the following holds:

$$
c_{i}\left(q_{i}\right)=0 \Rightarrow \xi_{j}^{N \backslash\{i\}}\left(Q_{-i}, C_{-i}, H_{-i}\right)=\xi_{j}(Q, C, H) \forall j \in N \backslash\{i\}
$$

Remark 9 Note that the premise of the condition as defined by Sprumont reads $q_{i}=0$. Thus, our condition is slightly stronger than his.

Remark 10 (INA) implies that $\xi_{i}(Q, C, H)=0 \forall i: q_{i}=0$, a property called no exploitation by some authors. However (INA) says more. If an agent with a null stand-alone cost is removed from the problem, this must not change the contributions of the remaining agents. This is a form of consistency. The Path Serial Principle implies the first part of (INA) but not the latter. Also note that (INA) implies Free Lunch, which Moulin and Shenker (1994) use to characterize the Serial Rule in the single private good context. It also implies another condition called Dummy in cooperative game theory and which says that if an agent does not affect the cost of any coalition that she might join, then her cost share must be zero.

\subsection{Monotonicity}

Another ethical condition that has received much attention in the literature on cost sharing is monotonicity of the cost shares with respect to own demands. The Path Serial Rule does not satisfy the original monotonicity condition in the general context but it satisfies a weaker form of this condition, called path monotonicity. Also examined in this subsection is the behaviour of the cost shares with respect to others' demands.

Definition 16 A cost sharing rule $\xi: \mathbb{R}_{+}^{m} \times \mathbb{C}(m) \times \mathcal{H} \rightarrow \mathbb{R}_{+}^{n}$ satisfies Demand Monotonicity (DM) if for two problems $(Q, C, H)$ and $\left(Q^{\prime}, C, H^{\prime}\right) \in \mathbb{R}_{+}^{m} \times \mathbb{C}(m) \times \mathcal{H}(C)$, and any $i \in N$ such that $q_{i} \leq q_{i}^{\prime}$ and $q_{j}=q_{j}^{\prime} \forall j \in N \backslash\{i\}$, we have $\xi_{i}(Q, C, H) \leq \xi_{i}\left(Q^{\prime}, C, H^{\prime}\right)$.

(DM) says that an agent should expect to pay more if he increases his demand. This does not imply that the other agents will not pay more as we shall see. Sprumont (1998) proves that the Axial Rule $\xi^{D S}$ satisfies (DM) in the context where $M_{i}=\{i\} \forall i$. We show in Téjédo-Truchon (2001) that this is not the case of the Radial Serial Rule $\xi^{R S}$ even in the homogeneous context. A fortiori, the Path Serial Rule $\xi^{P S}$ does not satisfy (DM) in the general context. This motivates the next definition. 
Definition 17 A cost sharing rule $\xi: \mathbb{R}_{+}^{m} \times \mathbb{C}(m) \times \mathcal{H} \rightarrow \mathbb{R}_{+}^{n}$ satisfies Path Demand Monotonicity (PDM) if for two problems $(Q, C, H)$ and $\left(Q^{\prime}, C, H\right) \in \mathbb{R}_{+}^{m} \times \mathbb{C}(m) \times \mathcal{H}(C)$, for any $i \in N$ such that $q_{i} \in h_{i}\left(q_{i}^{\prime}, \mathbb{R}_{+}\right), q_{i} \leq q_{i}^{\prime}$, and $q_{j}=q_{j}^{\prime} \forall j \in N \backslash\{i\}$, we have $\xi_{i}(Q, C, H) \leq \xi_{i}\left(Q^{\prime}, C, H\right)$.

Remark 11 According to Remark 4, the fact that $\xi^{D S}$ satisfies (DM) in $\mathbb{R}_{+}^{n} \times \mathbb{C}(n)$ implies that $\xi^{P S}$ satisfies (PDM). Nevertheless, we give a direct proof of this statement below.

There is not much that we can say in general on how the share of an agent $i$ varies under $\xi^{P S}$ with the demand of another agent $k$ whose stand-alone cost $c_{k}\left(q_{k}\right)$ is lower that $c_{i}\left(q_{i}\right)$. However, we shall show that this share cannot decrease when the cost function satisfies increasing incremental cost (IIC) and that it cannot increase when the cost function satisfies decreasing incremental cost (DIC).

Definition 18 A cost sharing rule $\xi: \mathbb{R}_{+}^{m} \times \mathbb{C}(m) \times \mathcal{H} \rightarrow \mathbb{R}_{+}^{n}$ satisfies Positive Path Cross Monotonicity (PPCM) if for two problems $(Q, C, H)$ and $\left(Q^{\prime}, C, H\right) \in \mathbb{R}_{+}^{m} \times \mathbb{C}(m) \times \mathcal{H}(C)$ such that $q_{k} \in h_{k}\left(q_{k}^{\prime}, \mathbb{R}_{+}\right)$and $q_{k} \leq q_{k}^{\prime}$ for some $k$ and $q_{j}=q_{j}^{\prime} \forall j \neq k$, we have $\xi_{i}(Q, C, H) \leq$ $\xi_{i}\left(Q^{\prime}, C, H\right) \forall i \in N /\{k\}$, i.e. $\xi_{i}$ is a non-decreasing function along the path $h_{k}\left(q_{k}, \mathbb{R}_{+}\right)$. It satisfies Negative Path Cross Monotonicity (NPCM) if, under the same circumstances, $\xi_{i}(Q, C, H) \geq \xi_{i}\left(Q^{\prime}, C, H\right) \forall i \in N /\{k\}$.

Theorem $6 \xi^{P S}$ satisfies (PM). It also satisfies (PPCM) or (NPCM) for any class of problems such that $C$ is respectively an IIC or a DIC cost function.

The proof is given in subsection 8.4 for $(\mathrm{PM})$ and (PPCM). It suffices to change the sense of the relevant inequalities to get (NPCM). Of course, we should expect the relation between $\xi_{i}^{P S}(Q, C, H)$ and $\xi_{i}^{P S}\left(Q^{\prime}, C, H\right)$ to hold when more than one component of $Q$ is increased to give $Q^{\prime}$. This is recorded in the following corollary.

Corollary 7 Consider two problems $(Q, C, H)$ and $\left(Q^{\prime}, C, H\right) \in \mathbb{R}_{+}^{m} \times \mathbb{C}(m) \times \mathcal{H}(C)$ such that $C$ is an IIC cost function, $q_{j} \in h_{j}\left(q_{j}^{\prime}, \mathbb{R}_{+}\right)$and $q_{j} \leq q_{j}^{\prime} \forall j$. Then $\xi_{i}^{P S}(Q, C, H) \leq$ $\xi_{i}^{P S}\left(Q^{\prime}, C, H\right) \forall i \in N$. Similarly, $\xi_{i}^{P S}(Q, C, H) \geq \xi_{i}^{P S}\left(Q^{\prime}, C, H\right) \forall i \in N$ when $C$ is a DIC cost function.

The proof is given in subsection 8.5.

Remark 12 Since the Axial Rule satisfies Ordinality, we can invoke Remark 4 without the restriction to normalized problems, to assert that this rule also satisfies Positive or Negative 
Cross Monotonicity for any class of problems in $\mathbb{R}_{+}^{n} \times \mathbb{C}(n)$ such that $C$ is respectively an IIC or a DIC cost function.

\subsection{Bounds for Cost Shares}

If they are free to decide, agents will choose to participate in a cost sharing problem only if they are guaranteed that their share of the cost will not be larger than their stand-alone cost. This is a condition that Moulin and Shenker (1992) calls participation. We show that the Path Serial Rule meets this condition whenever $C$ satisfies increasing benefit from cooperation, defined in Remark 2.

Actually, under (DIC), the Path Serial Rule satisfies a stronger property. Any coalition of agents is guaranteed that their total share of the cost will not be larger than their stand-alone cost as a coalition. In other words, the list of cost shares produced by the Path Serial Rule belongs to the core. We can actually go farther. Any cost sharing rule satisfying (PPCM) has the core property. As far as we can see, the relation between serial cost sharing and the core has not been addressed before in the literature.

Definition 19 A cost sharing rule $\xi: \mathbb{R}_{+}^{m} \times \mathbb{C}(m) \times \mathcal{H} \rightarrow \mathbb{R}_{+}^{n}$ satisfies Participation for a problem $(Q, C, H) \in \mathbb{R}_{+}^{m} \times \mathbb{C}(m) \times \mathcal{H}(C)$ if $\xi_{i}(Q, C, H) \leq c_{i}\left(q_{i}\right) \forall i \in N$.

Theorem 8 The Path Serial Rule $\xi^{P S}$ satisfies Participation for any class of problems $(Q, C, H) \in \mathbb{R}_{+}^{m} \times \mathbb{C}(m) \times \mathcal{H}(C)$ such that $C$ satisfies increasing benefit from cooperation.

The proof is given in subsection 8.6.

Definition 20 The Core $C o(Q, C, H)$ of a cost sharing problem $(Q, C, H)$ is the set of cost shares $x \in \mathbb{R}_{+}^{n}$ that satisfy:

$$
\begin{aligned}
\sum_{i \in S} x_{i} & \leq C\left(Q^{S}\right) \forall S \subset N \\
\sum_{i \in N} x_{i} & =C(Q)
\end{aligned}
$$

Definition 21 A cost sharing rule $\xi: \mathbb{R}_{+}^{m} \times \mathbb{C}(m) \times \mathcal{H} \rightarrow \mathbb{R}_{+}^{n}$ has the Core Property (CO) if $\xi(Q, C, H) \in C o(Q, C, H)$ for any problem $(Q, C, H) \in \mathbb{R}_{+}^{m} \times \mathbb{C}(m) \times \mathcal{H}(C)$.

Theorem 9 Any cost sharing rule $\xi: \mathbb{R}_{+}^{m} \times \mathbb{C}(m) \times \mathcal{H} \rightarrow \mathbb{R}_{+}^{n}$ satisfying (NPCM) and (INA) has the core property.

The proof is given in subsection 8.7. The following corollary is immediate. 
Corollary 10 The Path Serial Rule $\xi^{P S}$ has the core property (CO) for any class of problems $(Q, C, H) \in \mathbb{R}_{+}^{m} \times \mathbb{C}(m) \times \mathcal{H}(C)$ such that $C$ is a DIC cost function.

Remark 13 Participation follows obviously from the core property. However, we have been able to establish this property under the weaker increasing benefit from cooperation.

If the cost function satisfies (IIC) instead of (DIC), we should not expect all agents to be willing to cooperate since at least one of them will have to pay more than its stand-alone cost. However, there may be circumstances where agents are forced to cooperate even if the cost function satisfies (IIC). In such a case, we could impose that each agent pays at least its stand-alone cost. This can be seen as an equity condition, to which Moulin and Shenker (1992) gives a name. The Path Serial rule satisfies this condition under decreasing benefit from cooperation. Under (IIC), it satisfies a stronger condition, which is somewhat the opposite of the core property, namely no coalition can benefit from cooperation.

Definition 22 A cost sharing rule $\xi: \mathbb{R}_{+}^{m} \times \mathbb{C}(m) \times \mathcal{H} \rightarrow \mathbb{R}_{+}^{n}$ satisfies the Stand-Alone Test $(\mathrm{SAT})$ for a problem $(Q, C, H) \in \mathbb{R}_{+}^{m} \times \mathbb{C}(m) \times \mathcal{H}(C)$ if $\xi_{i}(Q, C, H) \geq c_{i}\left(q_{i}\right) \forall i \in N$.

Theorem 11 The Path Serial Rule $\xi^{P S}$ respects (SAT) for any class of problems $(Q, C, H) \in$ $\mathbb{R}_{+}^{m} \times \mathbb{C}(m) \times \mathcal{H}(C)$ such that $C$ satisfies decreasing benefit from cooperation.

Proof. Simply reverse the inequalities in the proof of Theorem 8.

Definition 23 A cost sharing rule $\xi: \mathbb{R}_{+}^{m} \times \mathbb{C}(m) \times \mathcal{H} \rightarrow \mathbb{R}_{+}^{n}$ satisfies the No Benefit from Cooperation $(\mathrm{NBC})$ for a problem $(Q, C, H) \in \mathbb{R}_{+}^{m} \times \mathbb{C}(m) \times \mathcal{H}(C)$ if:

$$
\sum_{i \in S} \xi_{i}(Q, C, H) \geq C\left(Q^{S}\right) \forall S \subset N
$$

Theorem $12 A$ cost sharing rule $\xi: \mathbb{R}_{+}^{m} \times \mathbb{C}(m) \times \mathcal{H} \rightarrow \mathbb{R}_{+}^{n}$ satisfying (PPCM) and (INA) also satisfies $(N B C)$.

Proof. Again, simply reverse the inequalities in the proof of Theorem 9.

Corollary 13 The Path Serial Rule $\xi^{P S}$ satisfies $(N B C)$ for any class of problems $(Q, C, H) \in$ $\mathbb{R}_{+}^{m} \times \mathbb{C}(m) \times \mathcal{H}(C)$ such that $C$ is an IIC cost function.

The other question of interest in the case of an IIC cost function is whether there is an upper bound on the contribution of each agent. In order to introduce such a bound, we first 
define for each $i$ an equal cost demand $\tilde{Q}^{i} \in \mathbb{R}_{+}^{m}$ by scaling the demands up or down so as to satisfy:

$$
\begin{array}{ll}
q_{j} \in h_{j}\left(\tilde{q}_{j}^{i}, \mathbb{R}_{+}\right) \text {and } c_{j}\left(\tilde{q}_{j}^{i}\right)=c_{i}\left(q_{i}\right) & \text { for } j<i \\
\tilde{q}_{j}^{i}=q_{j} & \text { for } j=i \\
\tilde{q}_{j}^{i} \in h_{j}\left(q_{j}, \mathbb{R}_{+}\right) \text {and } c_{j}\left(\tilde{q}_{j}^{i}\right)=c_{i}\left(q_{i}\right) & \text { for } j>i
\end{array}
$$

We then have the following condition.

Definition 24 A cost sharing rule $\xi: \mathbb{R}_{+}^{m} \times \mathbb{C}(m) \times \mathcal{H} \rightarrow \mathbb{R}_{+}^{n}$ satisfies the Equal Cost Bound (ECB) for a problem $(Q, C, H) \in \mathbb{R}_{+}^{m} \times \mathbb{C}(m) \times \mathcal{H}(C)$ if $\xi_{i}(Q, C, H) \leq \frac{C\left(\tilde{Q}^{i}\right)}{n} \forall i \in N$.

For a homogeneous problem, $C\left(\tilde{Q}^{i}\right)=c\left(n q_{i}\right)$. Thus, the condition generalizes the Unanimity Bound of Moulin and Shenker (1992). Clearly, $\xi^{P S}$ satisfies (ECB) for DIC cost functions. We shall now show that this bound is also satisfied for IIC cost functions.

Theorem 14 The Path Serial Rule $\xi^{P S}$ satisfies (ECB) for any class of problems $(Q, C, H) \in$ $\mathbb{R}_{+}^{m} \times \mathbb{C}(m) \times \mathcal{H}(C)$ such that $C$ is an IIC cost function.

Proof. Since $\tilde{q}_{j}^{i} \geq q_{j}^{i}=q_{j} \forall j<i$ and $\tilde{q}_{j}^{i}=q_{j}^{i} \forall j \geq i$, applying Corollary 7 , we have:

$$
\xi_{i}^{P S}(Q, C, H)=\xi_{i}^{P S}\left(Q^{i}, C, H\right) \leq \xi_{i}^{P S}\left(\tilde{Q}^{i}, C, H\right)=\frac{C\left(\tilde{Q}^{i}\right)}{n} \forall i \in N
$$

\subsection{Separation and Additivity}

Moulin and Shenker (1994) consider as a basic equity property that the contribution of each agent be proportional to his or her demand when cost is proportional to the quantities requested. We generalize this definition.

Definition 25 A cost sharing rule $\xi: \mathbb{R}_{+}^{m} \times \mathbb{C}(m) \times \mathcal{H} \rightarrow \mathbb{R}_{+}^{n}$ satisfies Separation (SC) if for any problem $(Q, C, H) \in \mathbb{R}_{+}^{m} \times \mathbb{C}(m) \times \mathcal{H}(C), \xi_{i}(Q, C, H)=c_{i}\left(q_{i}\right) \forall i \in N$ whenever $C$ is of the form $C(Y)=\sum_{i \in N} c_{i}\left(y_{i}\right)$.

Theorem $15 \xi^{P S}$ satisfies (SC).

The proof is given in subsection 8.8. 
Corollary $16 \xi_{i}^{P S}(Q, C, H)=\lambda_{i} \cdot q_{i} \forall i \in N$ whenever $C$ is of the form $C(Y)=\lambda \cdot Y$ where $\lambda_{i} \in \mathbb{R}_{+}^{m_{i}} \forall i \in N$ and $\lambda=\left(\lambda_{1}, \ldots, \lambda_{n}\right)$.

This last proposition is actually how Moulin and Shenker (1994) define (SC), more precisely separable cost, in the single private good context. Another separation condition is additivity in cost components.

Definition 26 A cost sharing rule $\xi: \mathbb{R}_{+}^{m} \times \mathbb{C}(m) \rightarrow \mathbb{R}_{+}^{n}$ satisfies Additivity (A) if $\forall C_{1}, C_{2} \in$ $\mathbb{C}(m), \forall Q \in \mathbb{R}_{+}^{m}$, the following hold:

$$
\xi\left(Q, C_{1}\right)+\xi\left(Q, C_{2}\right)=\xi\left(Q, C_{1}+C_{2}\right)
$$

Remark 14 Kolpin (1996) shows that there is no extension of the serial rule satisfying Scale Invariance (SI) and (A). Since the Path Serial Rule satisfies (SI), it does not satisfy (A). This is also true of the Axial and the Radial Serial Rules.

\section{Characterization of the Path Serial Rule}

Not surprisingly, paralleling the characterization of the original Serial Rule, the Path Serial Rule is the only cost sharing rule that satisfies Equal Treatment of Equivalents (ETV) and the Path Serial Principle (PSP). As far as we can see, there is no other characterization of this rule, contrary to what exists for the original Serial Rule and the Axial Serial Rule.

Theorem $17 \xi^{P S}$ is the only cost sharing rule that satisfies (ETV) and (PSP).

The proof is given in subsection 8.9 .

Remark 15 Combining Remarks 7 and 8, we get the following characterization. If a rule $\xi: \mathbb{R}_{+}^{m} \times \mathbb{C}(m) \times \mathcal{H} \rightarrow \mathbb{R}_{+}^{n}$ is defined from a rule $\xi^{N}: \mathbb{R}_{+}^{n} \times \mathbb{C}(n) \rightarrow \mathbb{R}_{+}^{n}$ by $\xi(Q, C, H)=\xi^{N}\left(\breve{c}(Q), c_{Q}^{H}\right)$ and if $\xi^{N}$ satisfies Independence of Larger Demands (ILD) and Equal Treatment of Equals (ETE) on the class of normalized problems, then $\xi=\xi^{P S}$.

Sprumont (1998) shows that the Axial Rule $\xi^{A}: \mathbb{R}_{+}^{n} \times \mathbb{C}(n) \rightarrow \mathbb{R}_{+}^{n}$ is the only cost sharing rule that satisfies Ordinality (O), (SP), Independence of Null Agents (INA), Rank Independence of Irrelevant Agents (RIIA), and Symmetry (S) in the context where $M_{i}=\{i\} \forall i$. From Theorem 5, we know that (ETE) and (SP) are incompatible in the general context. Since (ETE) implies (S), this means that $(\mathrm{S})$ and $(\mathrm{SP})$ are also incompatible. Thus, Sprumont's characterization of the Axial Serial rule does not carry over to the Path Serial 
Rule. Could we obtain a positive result by replacing (SP) with (PSP)? As it turns out, $\xi^{P S}$ satisfies (O), (PSP), (INA), (RIIA), and (S) but we exhibit another rule that satisfies the same conditions. Thus, adding (O), (INA), and (RIIA) to (PSP) does not compensate for the weakening of (ETV) into $(\mathrm{S})$ in the characterization of $\xi^{P S}$.

To define this other rule, we first partition $N$ into two arbitrary subsets $N_{1}$ and $N_{2}$ such that $m_{i}=m_{j}$ implies $\{i, j\} \subset N_{1}$ or $\{i, j\} \subset N_{2}$. Then, given a cost function $C \in \mathbb{C}(m)$ and the induced functions $c_{1}, \ldots, c_{n}$, let the functions $\hat{c}_{i}: \mathbb{R}_{+}^{m_{i}} \rightarrow \mathbb{R}_{+}, i=1, \ldots, n$, be defined by

$$
\hat{c}_{i}(y)= \begin{cases}c_{i}(y) & \text { if } i \in N_{1} \\ \theta c_{i}(y) & \text { if } i \in N_{2}\end{cases}
$$

where $\theta$ is any positive real number.

We now define a cost sharing rule that we call $\xi^{T}$ exactly as $\xi^{P S}$ except that the agents are ordered according to their $\hat{c}_{i}\left(q_{i}\right)$ :

$$
\hat{c}_{1}\left(q_{1}\right) \leq \hat{c}_{2}\left(q_{2}\right) \leq \ldots \leq \hat{c}_{n}\left(q_{n}\right)
$$

and the intermediate demands are constructed using the functions $\hat{c}_{i}$ instead of $c_{i}$. We note them $\hat{Q}^{1}, \ldots, \hat{Q}^{n}$. Actually, by varying $\theta$ and the partition of $N$, we can obtain a whole family of similar rules. Clearly, $\xi^{T}$ is different from $\xi^{P S}$ whenever $\theta \neq 1, N_{1} \neq \emptyset$, and $N_{2} \neq \emptyset$.

Theorem 18 The rule $\xi^{T}: \mathbb{R}_{+}^{m} \times \mathbb{C}(m) \times \mathcal{H} \rightarrow \mathbb{R}_{+}^{n}$ satisfies (O), (PSP), (INA), (RIIA), and $(S)$.

The proof is given in subsection 8.10.

Corollary 19 The Path Serial Rule $\xi^{P S}$ satisfies (O), (PSP), (INA), (RIIA), and (S).

Proof. $\xi^{P S}$ is $\xi^{T}$ with $\theta=1$.

For homogeneous problems, $\xi^{T}$ is exactly $\xi^{P S}$ since $m_{i}=m_{j} \forall i, j$. Thus, there still remains a possibility that, in the homogeneous context, $\xi^{P S}$ could be characterized in a way similar to the Axial Rule. Actually, as part of their Theorem 4.5, Koster et al. (1998) pretend to show that in the homogeneous context, a cost sharing rule that satisfies a condition that they call Radial Ordinality, the Radial Serial Principle, (INA), (RIIA), and (ETE) is the Radial Serial Rule $\xi^{R S}$. We show in Téjédo-Truchon (2001) that this is false. 


\section{Conclusion}

We have shown that Serial Cost Sharing Rule can be extended to the general context where agents request several commodities that can be public, private, or specific to some of them and where aggregation may be very general. Actually, aggregation may be so general as to involve optimization. We have defined the Path Serial Rule to meet this kind of problem. As it names implies, it consists in scaling down the demands along paths that are specified within the problem in order to construct the intermediate demands that are at the root of serial cost sharing. Put differently, the Path Serial Rule consists in applying the original Serial Cost Sharing Rule to a projection of each demand into the specified path.

We have been able to characterize the Path Serial Rule only by the Equal Treatment of Equivalents (demands) and the Path Serial Principle. The rule satisfies other properties such as Independence of Null Agents, Rank Independence of Irrelevant Agents, Ordinality,

and Path Demand Monotonicity. However, the latter and the Path Serial Principle are considerably weaker than the corresponding properties in the single private good context. Indeed, these properties say something about how cost shares should behave when demands change along the specified paths. Anything can happen for other types of changes in the demands.

\section{Proofs}

\subsection{Proof of Lemma 1}

1. Applying (1) iteratively to the triples $\left(Y+Z^{\{1, \ldots, i-1\}}, Y^{\prime}+Z^{\{1, \ldots, i-1\}}, Z\right)$ and the pair $(i, i), i=1, \ldots, n$, with $Z^{\emptyset}=0$, to get

$$
C\left(Y+Z^{\{1, \ldots, i\}}\right)-C\left(Y+Z^{\{1, \ldots, i-1\}}\right) \geq C\left(Y^{\prime}+Z^{\{1, \ldots, i\}}\right)-C\left(Y^{\prime}+Z^{\{1, \ldots, i-1\}}\right)
$$

and summing member-wise over $i$ yields (3).

2. Consider any increasing sequence $S_{1}, S_{2}, \ldots, S_{\# I(Z)}$ of proper subsets of $I(Z)$ such that $h$ belongs only to $S_{\# I(Z)}$ and let $S_{0}=\emptyset$. Note that $j$ is the cardinality of $S_{j}$ and that $Y+Z^{S_{j}} \leq Y^{\prime}, j=1, \ldots, \# I(Z)-1$. Thus, by (DIC), we can write

$$
C\left(Y+Z^{S_{j}}\right)-C\left(Y+Z^{S_{j-1}}\right) \geq C\left(Y^{\prime}+Z^{\{h\}}\right)-C\left(Y^{\prime}\right), j=1, \ldots, \# I(Z)
$$

with $Z^{S_{0}}=0$. Summing over all $j \in I(Z)$ yields (4). 
3. Consider the triples $\left(Y^{\{i\}}, Y^{\prime\{i\}}, \hat{Z}^{i}\right)$ where $\hat{Z}^{i}=\left(y_{1}, \ldots, y_{1-1}, 0, y_{1+1}^{\prime}, \ldots, y_{n}^{\prime}\right)$, $i=1, \ldots, n$. Then, using (3) on each triple, we get

$$
\begin{array}{r}
C\left(y_{1}, \ldots, y_{1-1}, y_{i}, y_{1+1}^{\prime}, \ldots, y_{n}^{\prime}\right)-C\left(0, \ldots, 0, y_{i}, 0, \ldots, 0\right) \\
\geq C\left(y_{1}, \ldots, y_{1-1}, y_{i}^{\prime}, y_{1+1}^{\prime}, \ldots, y_{n}^{\prime}\right)-C\left(0, \ldots, 0, y_{i}^{\prime}, 0, \ldots, 0\right)
\end{array}
$$

from which:

$$
\begin{aligned}
c_{i}\left(y_{i}^{\prime}\right)-c_{i}\left(y_{i}\right) & =C\left(0, \ldots, 0, y_{i}^{\prime}, 0, \ldots, 0\right)-C\left(0, \ldots, 0, y_{i}, 0, \ldots, 0\right) \\
& \geq C\left(y_{1}, \ldots, y_{1-1}, y_{i}^{\prime}, y_{1+1}^{\prime}, \ldots, y_{n}^{\prime}\right)-C\left(y_{1}, \ldots, y_{1-1}, y_{i}, y_{1+1}^{\prime}, \ldots, y_{n}^{\prime}\right)
\end{aligned}
$$

Summing member-wise over $i$ yields (5).

\subsection{Proof of Lemma 3}

Let $f: \mathbb{R}_{+}^{m} \rightarrow \mathbb{R}_{+}^{m}$ be the ordinal transformation. Thus, we have $Q=f\left(Q^{\prime}\right), h_{i}\left(q_{i}, \mathbb{R}_{+}\right)=$ $f_{i}\left(h^{\prime}\left(q_{i}^{\prime}, \mathbb{R}_{+}\right)\right) \forall i$, and $C^{\prime}(Y)=C(f(Y)) \forall y \in \mathbb{R}_{+}^{m}$. The latter implies

$$
c_{i}^{\prime}(y)=c_{i}\left(f_{i}(y)\right) \quad \forall y \in \mathbb{R}_{+}^{m_{i}} \forall i \in N
$$

and:

$$
c_{i}^{\prime}\left(q_{i}^{\prime}\right)=c_{i}\left(q_{i}\right) \quad \forall i \in N
$$

In short, $\breve{c}\left(Q^{\prime}\right)=\breve{c}(Q)$. Next, we show that $c_{Q^{\prime}}^{H^{\prime}}=c_{Q}^{H}$. Given a $x \in \mathbb{R}_{+}^{n}$ and a $i \in N$, let $\tau$ and $\tau^{\prime}$ be two real numbers such that

$$
c_{i}\left(h_{i}\left(q_{i}, \tau\right)\right)=x_{i}=c_{i}^{\prime}\left(h_{i}^{\prime}\left(q_{i}^{\prime}, \tau^{\prime}\right)\right)=c_{i}\left(f_{i}\left(h_{i}^{\prime}\left(q_{i}^{\prime}, \tau^{\prime}\right)\right)\right)
$$

Since the two problems are ordinally equivalent, $h_{i}\left(q_{i}, \mathbb{R}_{+}\right)=f_{i}\left(h_{i}^{f}\left(q_{i}^{f}, \mathbb{R}_{+}\right)\right)$, i.e. $h_{i}\left(q_{i}, \tau\right)$ and $f_{i}\left(h_{i}^{\prime}\left(q_{i}^{\prime}, \tau^{\prime}\right)\right)$ are both on the path $h_{i}\left(q_{i}, \mathbb{R}_{+}\right)$. Since $c_{i}\left(h_{i}\left(q_{i}, \cdot\right)\right)$ is an increasing function, $c_{i}\left(h_{i}\left(q_{i}, \tau\right)\right)=c_{i}\left(f_{i}\left(h_{i}^{\prime}\left(q_{i}^{\prime}, \tau^{\prime}\right)\right)\right)$ implies $h_{i}\left(q_{i}, \tau\right)=f_{i}\left(h_{i}^{\prime}\left(q_{i}^{\prime}, \tau^{\prime}\right)\right)$. Using the latter with $c_{i q_{i}}^{-1}\left(x_{i}\right)=h_{i}(y, \tau)$, and $c_{i q_{i}}^{\prime-1}\left(x_{i}\right)=h_{i}^{\prime}\left(q_{i}^{\prime}, \tau^{\prime}\right)$, we get:

$$
\begin{aligned}
c_{Q^{\prime}}^{H^{\prime}}(x) & =C^{\prime}\left(c_{1 q_{1}^{\prime}}^{\prime-1}\left(x_{1}\right), \ldots, c_{n q_{n}^{\prime}}^{-1}\left(x_{n}\right)\right)=C\left(f\left(c_{1 q_{1}^{\prime}}^{\prime-1}\left(x_{1}\right), \ldots, c_{n q_{n}^{\prime}}^{\prime-1}\left(x_{n}\right)\right)\right) \\
& =C\left(c_{1 q_{1}}^{-1}\left(x_{1}\right), \ldots, c_{n q_{n}}^{-1}\left(x_{n}\right)\right)=c_{Q}^{H}(x)
\end{aligned}
$$




\subsection{Proof of Theorem 5}

Let $\xi$ satisfies (ETE) and (SP) and consider two homogeneous problems $(Q, C, H)$ and $(\tilde{Q}, C, H) \in \mathbb{R}_{+}^{n k} \times \mathbb{C}(n k) \times \mathcal{H}(C)$ such that:

$$
\begin{gathered}
q_{1}=\tilde{q}_{1} \leq \tilde{q}_{j}, j=2, \ldots, n \\
q_{j} \leq \tilde{q}_{j}, j=2, \ldots, n \\
\xi_{i}(Q, C, H) \leq \xi_{j}(Q, C, H) \forall i<j
\end{gathered}
$$

Note that (10) implies:

$$
\xi_{1}(Q, C, H) \leq \frac{C(Q)}{n}
$$

Next, consider the following profile of demands $Q^{1}=\left(q_{1}, \ldots, q_{1}\right)$. By (ETE):

$$
\xi_{1}\left(Q^{1}, C, H\right)=\frac{C\left(Q^{1}\right)}{n}
$$

By (SP), (8) and (10) imply:

$$
\xi_{1}(\tilde{Q}, C, H)=\xi_{1}\left(Q^{1}, C, H\right)
$$

Similarly, (9) and (10) imply:

$$
\xi_{1}(\tilde{Q}, C, H)=\xi_{1}(Q, C, H)
$$

Note that the form of $H$ does not matter in the above. Combining (11-14), we get:

$$
C(Q) \geq C\left(Q^{1}\right)
$$

This last inequality is not satisfied for all cost functions. Consider for example the two profiles:

$$
Q=((2,1),(1,2)) \quad \tilde{Q}=((2,1),(2,3))
$$

We have:

$$
Q^{1}=((2,1),(2,1))
$$

Inequality (15) is violated for example with the following class of homogeneous cost functions defined by

$$
C(Y)=g\left(\left(y_{11}+y_{21}\right)^{3}+\left(y_{12}+y_{22}\right)^{3}\right)
$$

where $g: \mathbb{R}_{+} \rightarrow \mathbb{R}_{+}, g^{\prime}(\cdot)>0$, and otherwise arbitrary. 


\subsection{Proof of Theorem 6}

Consider two problems $(Q, C, H)$ and $\left(Q^{\prime}, C, H\right) \in \mathbb{R}_{+}^{m} \times \mathbb{C}(m) \times \mathcal{H}(C)$ such that $C$ is an IIC cost function and such that $q_{k} \in h_{k}\left(q_{k}^{\prime}, \mathbb{R}_{+}\right), q_{k}^{\prime} \geq q_{k}$ and $q_{j}^{\prime}=q_{j} \forall j \neq k$. We shall show that $\xi_{i}^{P S}(Q, C, H) \leq \xi_{i}^{P S}\left(Q^{\prime}, C, H\right) \forall i \in N$. We first suppose that $c_{1}\left(q_{1}\right) \leq c_{2}\left(q_{2}\right) \leq \ldots \leq c_{n}\left(q_{n}\right)$ and $c_{1}\left(q_{1}^{\prime}\right) \leq c_{2}\left(q_{2}^{\prime}\right) \leq \ldots \leq c_{n}\left(q_{n}^{\prime}\right)$. We must distinguish four cases:

- $i<k$ : In this case, $\xi_{i}^{P S}\left(Q^{\prime}, C, H\right)=\xi_{i}^{P S}(Q, C, H)$ by (PSP).

- $i=k$ : In this case, $\xi_{i}^{P S}\left(Q^{\prime}, C, H\right) \geq \xi_{i}^{P S}(Q, C, H)$ since $C\left(Q^{\prime i}\right) \geq C\left(Q^{i}\right), C\left(Q^{\prime i-1}\right)=$ $C\left(Q^{i-1}\right)$, and $\xi_{j}^{P S}\left(Q^{\prime}, C, H\right)=\xi_{j}^{P S}(Q, C, H) \forall j<k$. This, together with the complement given below for the case where the ranks of the agents are changed when going from $Q$ to $Q^{\prime}$, establishes (PM).

- $i=k+1$ : Note that

$$
\xi_{k+1}^{P S}(Q, C, H)=\sum_{j=1}^{k-1} \xi_{j}^{P S}(Q, C, H)+\frac{C\left(Q^{k}\right)-C\left(Q^{k-1}\right)}{n-k+1}+\frac{C\left(Q^{k+1}\right)-C\left(Q^{k}\right)}{n-k}
$$

By (PSP), we know that $\xi_{j}^{P S}\left(Q^{\prime}, C, H\right)=\xi_{j}^{P S}(Q, C, H) \forall j<k$. We shall show that

$$
\begin{aligned}
& \frac{C\left(Q^{k}\right)-C\left(Q^{k-1}\right)}{n-k+1}+\frac{C\left(Q^{k+1}\right)-C\left(Q^{k}\right)}{n-k} \\
\leq & \frac{C\left(Q^{\prime k}\right)-C\left(Q^{\prime k-1}\right)}{n-k+1}+\frac{C\left(Q^{\prime k+1}\right)-C\left(Q^{\prime k}\right)}{n-k}
\end{aligned}
$$

which is equivalent to:

$$
C\left(Q^{\prime k}\right)-C\left(Q^{k}\right) \leq(n-k+1)\left(C\left(Q^{\prime k+1}\right)-C\left(Q^{k+1}\right)\right)
$$

This is a necessary condition for $\xi_{k+1}^{P S}(Q, C, H) \leq \xi_{k+1}^{P S}\left(Q^{\prime}, C, H\right)$ to hold.

Let $Y=Q^{k}, Y^{\prime}=Q^{k+1}, Z=Q^{\prime k}-Q^{k}=\left(0, \ldots, 0, q_{k}^{\prime k}-q_{k}^{k}, \ldots, q_{n}^{\prime k}-q_{n}^{k}\right)$ and note that $Q^{\prime k+1}-Q^{k+1}=Z^{\{k\}}$. By definition, we have $c_{j}\left(q_{j}^{\prime k}\right)=c_{k}\left(q_{k}^{\prime}\right)$ and $c_{j}\left(y_{j}\right)=$ $c_{j}\left(q_{j}^{k}\right)=c_{k}\left(q_{k}\right)=c_{k}\left(y_{k}\right) \forall j \geq k$, from which $c_{j}\left(q_{j}^{\prime k}\right)-c_{j}\left(q_{j}^{k}\right)=c_{k}\left(q_{k}^{\prime}\right)-c_{k}\left(q_{k}\right)$, i.e. $c_{j}\left(y_{j}+z_{j}\right)-c_{j}\left(y_{j}\right)=c_{k}\left(y_{k}+z_{k}\right)-c_{k}\left(y_{k}\right) \forall i, j \geq k$. Also note that $Y+Z=Q^{\prime k} \leq$ $Q^{\prime k+1}=Y^{\prime}+Z^{\{k\}}$. Thus, (16) follows from Lemma 1.2 and more precisely from (4) with the reversed inequality.

- $i>k+1$ : In this case, $Q^{i}-Q^{i}=Q^{i-1}-Q^{i-1}$, with $q_{k}^{\prime}-q_{k}$ as the only positive component and $Q^{i-1} \leq Q^{i}$. Thus, $C\left(Q^{i-1}\right)-C\left(Q^{i-1}\right) \leq C\left(Q^{i}\right)-C\left(Q^{i}\right)$ by (IIC) or 
Lemma 1.1, from which $C\left(Q^{i}\right)-C\left(Q^{i-1}\right) \leq C\left(Q^{\prime i}\right)-C\left(Q^{\prime i-1}\right)$. Combining this last inequality with $\xi_{j}^{P S}(Q, C, H) \leq \xi_{j}^{P S}\left(Q^{\prime}, C, H\right) \forall j<i$ yields the result.

Next, suppose that the order of the stand-alone costs is changed when going from $Q$ to $Q^{\prime}$. More precisely, suppose that $c_{k+p}\left(q_{k+p}^{\prime}\right)<c_{k}\left(q_{k}^{\prime}\right)$ for some $p \leq n-k$ and $c_{k}\left(q_{k}^{\prime}\right) \leq c_{k+p+1}\left(q_{k+p+1}^{\prime}\right)$ whenever $k+p+1 \leq n$. Then, consider a sequence $Q=$ $\hat{Q}^{0}, \hat{Q}^{1}, \ldots, \hat{Q}^{p}=Q^{\prime}$, where $\hat{q}_{j}^{\ell}=q_{j} \forall j \neq k$ and where $\hat{q}_{k}^{\ell}$ is chosen so that $q_{k} \in$ $h_{k}\left(\hat{q}_{k}^{\ell}, \mathbb{R}_{+}\right)$and $c_{k}\left(\hat{q}_{k}^{\ell}\right)=c_{k+\ell}\left(q_{k+\ell}\right), \ell=1, \ldots, p-1$. In other words, $\hat{Q}^{1}$ is obtained by increasing $q_{k}$ to get a $\hat{q}_{k}^{1}$ such that $q_{k} \in h_{k}\left(\hat{q}_{k}^{1}, \mathbb{R}_{+}\right)$and $c\left(\hat{q}_{k}^{1}\right)=c_{k+1}\left(q_{k+1}\right)$. $\hat{Q}^{2}$ is obtained by further increasing $q_{k}$ until its stand-alone cost reaches $c_{k+2}\left(q_{k+2}\right)$ and so on until $\hat{Q}^{p}$. Note that the ranks $k$ and $k+\ell$ may be interchanged in each of the problems $\left(\hat{Q}^{\ell}, C, H\right), \ell=1, \ldots, p$, without changing the cost shares for each problem under $\xi^{P S}$. Therefore, $\xi_{i}^{P S}$ is non-decreasing along this sequence of problems and thus:

$$
\xi_{i}^{P S}(Q, C, H) \leq \xi_{i}^{P S}\left(\hat{Q}^{1}, C, H\right) \leq \xi_{i}^{P S}\left(\hat{Q}^{p}, C, H\right)=\xi_{i}^{P S}\left(Q^{\prime}, C, H\right)
$$

\subsection{Proof of Corollary 7}

Consider a sequence $Q=\hat{Q}^{0}, \hat{Q}^{1}, \ldots, \hat{Q}^{n}=Q^{\prime}$, where:

$$
\hat{q}_{j}^{i}=\left\{\begin{array}{lll}
q_{j}^{\prime} & \text { if } & j \leq i \\
q_{j} & \text { if } & j>i
\end{array}\right.
$$

In plain word, each component is increased, if needed, one at a time along this sequence until $Q^{\prime}$ is reached. Then, by Theorem $6, \xi_{i}^{P S}$ is non-decreasing along the sequence of problems $\left(\hat{Q}^{i}, C, H\right), i=1, \ldots, n$, and thus:

$$
\xi_{i}^{P S}(Q, C, H) \leq \xi_{i}^{P S}\left(\hat{Q}^{1}, C, H\right) \leq \cdots \leq \xi_{i}^{P S}\left(\hat{Q}^{n}, C, H\right)=\xi_{i}^{P S}\left(Q^{\prime}, C, H\right)
$$

\subsection{Proof of Theorem 8}

We proceed by induction. With $Y=0$ and $Y^{\prime}=Q^{1}$ in $(5)$, we get $C\left(Q^{1}\right) \leq n c_{1}\left(q_{1}\right)$, from which:

$$
\xi_{1}(Q, C, H)=\frac{C\left(Q^{1}\right)}{n} \leq c_{1}\left(q_{1}\right)
$$


Next, suppose that $\xi_{i-1} \leq c_{i-1}\left(q_{i-1}\right)$ is true and note that:

$$
\begin{aligned}
\sum_{j=1}^{n} c_{j}\left(q_{j}^{i}\right) & =\sum_{j=1}^{i-1} c_{j}\left(q_{j}\right)+(n-i+1) c_{i}\left(q_{i}\right) \\
\sum_{j=1}^{n} c_{j}\left(q_{j}^{i-1}\right) & =\sum_{j=1}^{i-1} c_{j}\left(q_{j}\right)+(n-i+1) c_{i-1}\left(q_{i-1}\right)
\end{aligned}
$$

Then, (5) of Lemma 1.3 implies:

$$
C\left(Q^{i}\right)-C\left(Q^{i-1}\right) \leq(n-i+1)\left[c_{i}\left(q_{i}\right)-c_{i-1}\left(q_{i-1}\right)\right]
$$

Collecting all the above yields:

$$
\begin{aligned}
\xi_{i}(Q, C, H) & =\xi_{i-1}(Q, C, H)+\frac{C\left(Q^{i}\right)-C\left(Q^{i-1}\right)}{n-i+1} \\
& \leq c_{i-1}\left(q_{i-1}\right)+\frac{C\left(Q^{i}\right)-C\left(Q^{i-1}\right)}{n-i+1} \\
& \leq c_{i}\left(q_{i}\right)
\end{aligned}
$$

\subsection{Proof of Theorem 9}

Consider a problem $(Q, C, H) \in \mathbb{R}_{+}^{m} \times \mathbb{C}(m) \times \mathcal{H}(C)$ and any proper subset $S \subset N$. Let $\tilde{Q}$ be the profile of demands obtained by substituting $h_{j}\left(q_{j}, 0\right)$ to $q_{j}$ in $Q$ for all $j \notin S$. By

definition of $\mathcal{H}(C)$, we have $c_{j}\left(h_{j}\left(q_{j}, 0\right)\right)=0$. By (INA), we thus have $\xi_{i}(\tilde{Q}, C, H)=0$ $\forall i \notin S$, from which

$$
\sum_{i \in S} \xi_{i}(\tilde{Q}, C, H)=\sum_{i \in N} \xi_{i}(\tilde{Q}, C, H)=C(\tilde{Q})=C\left(Q^{S}\right)
$$

where the last equality follows from the definition of $\mathbb{C}(m)$. By (NPCM) and the fact that $Q^{S} \leq \tilde{Q}$, we also have:

$$
\sum_{i \in S} \xi_{i}(Q, C, H) \leq \sum_{i \in S} \xi_{i}(\tilde{Q}, C, H)=C\left(Q^{S}\right)
$$

We thus conclude that $\xi(Q, C, H) \in C o(Q, C, H)$.

\subsection{Proof of Theorem 15}

Suppose that $C$ is of the form $C(Y)=\sum_{i \in N} c_{i}\left(y_{i}\right)$ and let the agents be ordered by their stand alone costs, i.e. $c_{1}\left(q_{1}\right) \leq \ldots \leq c_{n}\left(q_{n}\right)$. We shall proceed by induction. It is easy to check that $\xi_{1}^{P S}(Q, C, H)=c_{1}\left(q_{1}\right)$. Next, suppose that for agent $i-1$, we have:

$$
\xi_{i-1}^{P S}(Q, C, H)=c_{i-1}\left(q_{i-1}\right)
$$


By definition, we know that:

$$
\xi_{i}^{P S}(Q, C, H)=\xi_{i-1}^{P S}(Q, C, H)+\frac{C\left(Q^{i}\right)-C\left(Q^{i-1}\right)}{n-i+1}
$$

By assumption and construction,

$$
\begin{aligned}
C\left(Q^{i}\right) & =\sum_{j=1}^{i-1} c_{j}\left(q_{j}\right)+(n-i+1) c_{i}\left(q_{i}\right) \\
C\left(Q^{i-1}\right) & =\sum_{j=1}^{i-1} c_{j}\left(q_{j}\right)+(n-i+1) c_{i-1}\left(q_{i-1}\right)
\end{aligned}
$$

Combining (17-20), we get:

$$
\xi_{i}^{P S}(Q, C, H)=c_{i}\left(q_{i}\right)
$$

Since this is true for any $i \in N, \xi^{P S}$ satisfies (SC).

\subsection{Proof of Theorem 17}

As pointed out in Remarks 7 and $8, \xi^{P S}$ satisfies (ETV) and (PSP). Turning to the converse, let $\xi$ a be cost sharing rule that satisfies (ETV) and (PSP) and given a problem $(Q, C, H) \in \mathbb{R}_{+}^{m} \times \mathbb{C}(m) \times \mathcal{H}(C)$ consider the sequence of cost sharing problems $\left(Q^{1}, C, H\right),\left(Q^{2}, C, H\right), \ldots,\left(Q^{n}, C, H\right)$ where the $Q^{i}$ are the intermediate demands of Definition 3. By (ETV), we have:

$$
\xi_{i}\left(Q^{1}, C, H\right)=\frac{C\left(Q^{1}\right)}{n} \forall i \in N
$$

By (PSP), we have:

$$
\xi_{1}(Q, C, H)=\xi\left(Q^{1}, C, H\right)
$$

By (ETV), we have:

$$
\xi_{i}\left(Q^{2}, C, H\right)=\sum_{j=1}^{2} \frac{C\left(Q^{j}\right)-C\left(Q^{j-1}\right)}{n+1-j} \forall i \in N \backslash\{1\}
$$

By (PSP), we have:

$$
\xi_{2}(Q, C, H)=\xi\left(Q^{2}, C, H\right)
$$

and so on. Thus, $\xi(Q, C, H)=\xi^{P S}(Q, C, H)$. 


\subsection{Proof of Theorem 18}

(S): Recall that agents are ordered according to the $\hat{c}_{i}\left(q_{i}\right)$. Let $C$ be symmetric and $q_{i}=q_{j}$ with $i<j$. Then, $\{i, j\} \subset N_{1}$ or $\{i, j\} \subset N_{2}$ and thus, $\hat{c}_{i}\left(q_{i}\right)=\hat{c}_{k}\left(q_{k}\right) \forall k: i \leq k \leq j$. This implies $\hat{Q}^{i}=\hat{Q}^{k} \forall k: i \leq k \leq j$. Thus $\xi_{i}^{T}(Q, C, H)=\xi_{j}^{T}(Q, C, H)$ as requested by (S).

(INA): Suppose that we remove an agent $k$ such that $c_{k}\left(q_{k}\right)=0$ from a cost sharing problem. If $k>1$, we have $\xi_{i}^{T}(Q, C, H)=0 \forall i \leq k$. Removing $k$ from the problem does not change the contribution of agents $i<k$. For agents $i>k$, this amounts to removing the term of index $k$ and replacing the term of index $k+1$ by $\frac{C\left(\hat{Q}^{k+1}\right)-C\left(\hat{Q}^{k-1}\right)}{n-k}$ in:

$$
\xi_{i}^{T}(Q, C, H)=\sum_{j=1}^{i} \frac{C\left(\hat{Q}^{j}\right)-C\left(\hat{Q}^{j-1}\right)}{n+1-j}, i=k+1, \ldots, n
$$

Since $\hat{Q}^{k}=\hat{Q}^{k-1}$, this leaves the contributions of these agents intact as requested by (INA). (RIIA): Consider two cost sharing problems $(Q, C, H)$ and $\left(Q^{\prime}, C, H^{\prime}\right) \in \mathbb{R}_{+}^{m} \times \mathbb{C}(m) \times \mathcal{H}(C)$ such that $q_{i}=q_{i}^{\prime}$ and $q_{j}=q_{j}^{\prime}$ for some $i, j \in N$. If $\xi_{i}^{T}(Q, C, H) \leq \xi_{j}^{T}(Q, C, H)$, then $C\left(\hat{Q}^{i}\right) \leq C\left(\hat{Q}^{j}\right)$, which in turns means that $\hat{c}_{i}\left(q_{i}\right) \leq \hat{c}_{j}\left(q_{j}\right)$. Thus, $\hat{c}_{i}\left(q_{i}^{\prime}\right) \leq \hat{c}_{j}\left(q_{j}^{\prime}\right)$, which implies $C\left(\hat{Q}^{\prime i}\right) \leq C\left(\hat{Q}^{\prime j}\right)$ and $\xi_{i}^{T}\left(Q^{\prime}, C, H^{\prime}\right) \leq \xi_{j}^{T}\left(Q^{\prime}, C, H^{\prime}\right)$. The converse is also true, i.e. $\xi_{i}^{T}\left(Q^{\prime}, C, H^{\prime}\right) \leq \xi_{j}^{T}\left(Q^{\prime}, C, H^{\prime}\right)$ implies $\xi_{i}^{T}(Q, C, H) \leq \xi_{j}^{T}(Q, C, H)$. Hence, $\xi_{i}^{T}(Q, C, H) \leq$ $\xi_{j}^{T}(Q, C, H) \Leftrightarrow \xi_{i}^{T}\left(Q^{\prime}, C, H^{\prime}\right) \leq \xi_{j}^{T}\left(Q^{\prime}, C, H^{\prime}\right)$ as requested by (RIIA).

(PSP): Consider two cost sharing problems $(Q, C, H)$ and $\left(Q^{\prime}, C, H\right) \in \mathbb{R}_{+}^{m} \times \mathbb{C}(m) \times \mathcal{H}(C)$, and a $i \in N$ such that $q_{i}^{\prime}=q_{i}$ and

$$
\begin{array}{ll}
q_{j}^{\prime}=q_{j} & \forall j \in N \backslash\{i\}: \xi_{j}(Q, C, H)<\xi_{i}(Q, C, H) \\
q_{j} \in h_{j}\left(q_{j}^{\prime}, \mathbb{R}_{+}\right) \text {and } q_{j}^{\prime} \geq q_{j} & \forall j \in N \backslash\{i\}: \xi_{i}(Q, C, H) \leq \xi_{j}(Q, C, H)
\end{array}
$$

Since $q_{j}^{\prime}$ and $q_{j}$ are on the same path for $j \in N \backslash\{i\}: \xi_{i}(Q, C, H) \leq \xi_{j}(Q, C, H)$, we clearly have $\hat{Q}^{j}=\hat{Q}^{\prime j}$ for $j=i$ and $j \in N \backslash\{i\}: \xi_{j}^{T}(Q, C, H)<\xi_{i}^{T}(Q, C, H)$. Thus, for those $j$, we have $\xi_{j}^{T}\left(Q^{\prime}, C, H\right)=\xi_{j}^{T}(Q, C, H)$ as requested by (PSP).

(O): Consider two ordinally equivalent problems $(Q, C, H) \in \mathbb{R}_{+}^{m} \times \mathbb{C}(m) \times \mathcal{H}(C)$ and $\left(Q^{f}, C^{f}, H^{f}\right) \in \mathbb{R}_{+}^{m} \times \mathbb{C}(m) \times \mathcal{H}\left(C^{f}\right)$ with $f: \mathbb{R}_{+}^{m} \rightarrow \mathbb{R}_{+}^{m}$ as the ordinal transformation. Thus, we have $Q=f\left(Q^{f}\right), h_{i}\left(q_{i}, \mathbb{R}_{+}\right)=f_{i}\left(h^{f}\left(q_{i}^{f}, \mathbb{R}_{+}\right)\right) \forall i$, and $C^{f}(Y)=C(f(Y)) \forall y \in \mathbb{R}_{+}^{m}$. The latter implies

$$
c_{i}^{f}(y)=c_{i}\left(f_{i}(y)\right) \quad \forall y \in \mathbb{R}_{+}^{m_{i}} \forall i \in N
$$


and:

$$
c_{i}^{f}\left(q_{i}^{f}\right)=c_{i}\left(q_{i}\right) \quad \forall i \in N
$$

This means that the transformation $f$ leaves the order of agents unchanged. Next, we show that $Q^{i}=f\left(Q^{f i}\right) \forall i \in N$. Given $i, j \in N$, let $\tau$ and $\tau^{f}$ be two real numbers such that $c_{j}\left(h_{j}\left(q_{j}, \tau\right)\right)=c_{i}\left(q_{i}\right)$ and $c_{j}^{f}\left(h_{j}^{f}\left(q_{j}^{f}, \tau^{f}\right)\right)=c_{i}^{f}\left(q_{i}^{f}\right)$. By definition:

$$
c_{j}\left(h_{j}\left(q_{j}, \tau\right)\right)=c_{i}\left(q_{i}\right)=c_{i}^{f}\left(q_{i}^{f}\right)=c_{j}^{f}\left(h_{j}^{f}\left(q_{j}^{f}, \tau^{f}\right)\right)=c_{j}\left(f_{j}\left(h_{j}^{f}\left(q_{j}^{f}, \tau^{f}\right)\right)\right)
$$

By definition, $h_{j}\left(q_{j}, \mathbb{R}_{+}\right)=f_{j}\left(h_{j}^{f}\left(q_{j}^{f}, \mathbb{R}_{+}\right)\right)$. Thus, $h_{j}\left(q_{j}, \tau\right)$ and $f_{j}\left(h_{j}^{f}\left(q_{j}^{f}, \tau^{f}\right)\right)$ are both on the path $h_{j}\left(q_{j}, \mathbb{R}_{+}\right)$. Since $c_{j}\left(h_{j}\left(q_{j}, \cdot\right)\right)$ is increasing, $c_{j}\left(h_{j}\left(q_{j}, \tau\right)\right)=c_{j}\left(f_{j}\left(h_{j}^{f}\left(q_{j}^{f}, \tau^{f}\right)\right)\right)$ implies $h_{j}\left(q_{j}, \tau\right)=f_{j}\left(h_{j}^{f}\left(q_{j}^{f}, \tau^{f}\right)\right)$. Thus, $Q^{i}=f\left(Q^{f i}\right)$, which implies $C^{f}\left(Q^{f i}\right)=C\left(Q^{i}\right)$ and $\xi^{P S}\left(Q^{f}, C^{f}, H\right)=\xi^{P S}\left(Q, C, H^{f}\right)$ as requested by $(\mathrm{O})$. 


\section{References}

[1] Kolpin V. (1996) "Multi-Product Serial Cost Sharing: an Incompatibility with the Additivity Axiom," Journal of Economic Theory, 69, 227-233.

[2] Koster M., Tijs S., and Borm P. (1998) "Serial Cost Sharing Methods for Multicommodity Situations," Mathematical Social Science, 36, 229-242.

[3] Moulin H. and Shenker S. (1992) "Serial Cost Sharing," Econometrica, 60, 1009-1037.

[4] Moulin H. and Shenker S. (1994) "Average Cost Pricing versus Serial Cost Sharing: An Axiomatic Comparison," Journal of Economic Theory, 64, 178-201.

[5] Shenker S. (1990) "Making Greed Work in Networks: A Game-Theoretic Analysis of Gateway Service Disciplines," Mimeo, Xerox Research Center, Palo Alto.

[6] Sprumont Y. (1998) "Ordinal Cost Sharing," Journal of Economic Theory, 81, 126-162.

[7] Téjédo C. and Truchon M., "The Radial Serial Cost Sharing Rule with General Aggregation", mimeo, 2001. 
91-01 HANEL, Petr, Standards in International Trade. A Canadian Perspective. (Paru dans Revue Canadienne des Sciences de l'Administration - Canadian Journal of Administrative Sciences, vol. 10.1, Mars 1993).

91-02 FORTIN, Mario, La réforme de l'impôt sur le revenu des particuliers: A-t-on vraiment abaissé les taux d'imposition?

91-03 ASCAH, Louis, Attribution of Pension Fund Surpluses: An Economic Perspective. (Published by Canadian Centre for Policy Alternatives, Ottawa).

91-04 ASCAH, Louis, Attribution du surplus d'un régime de retraite - un regard économique. (Publié par Centre canadien de recherche en politiques de rechange, Ottawa).

91-05 ASCAH, Louis, Recent Federal and Provincial Private Pension Plan Reform Legislation: Missing, Misleading and Shrinking Proposals (Published by Canadian Centre for Policy Alternatives, Ottawa). ASCAH, Louis, La comptabilité des déficits publics : des illusions à la réalité. ALLIE, E., R. DAUPHIN et M. FORTIN, Les aspirations de fertilité des étudiants de l'Université de Sherbrooke. HANEL, PETR, The Liberalization of International Trade in Czechoslovakia, Hungary, and Poland. (Paru dans Comparative Economic Studies, vol. 34, no 3-4, Fall-Winter 1992. ASCAH, Louis, Public Pension Theory for the Real World. FORTIN, Mario, L'écart des taux de chômage canadien et américain. BILODEAU, Marc et AI SLIVINSKI, Rational Nonprofit Entrepreneurship. FORTIN, Mario, The Impact of Unemployment Insurance on the Unemployment Rate. GENTZOGLANIS, Anastassios, Innovation and Competition in the High - and Medium - Intensity R\&D Industries.

93-05 FORTIN, Mario et A. ABDELKRIM, Sectoral Shifts, Stock Market Dispersion and Unemployment in Canada. (Paru dans Applied Economics, volume 29, pp. 829-839, juin 1997.)

93-06 HANEL, Petr, Interindustry Flows of Technology: An Analysis of the Canadian Patent Matrix and Input-Output Matrix for 1978-1989. (Paru dans Technovation, vol 14, no. 8, October 1994.

94-01 BILODEAU, Marc et AI SLIVINSKI, Toilet Cleaning and Department Chairing: Volunteering a Public Service. (À paraître dans Journal of Public Economics)

94-02 ASCAH, Louis, Recent Retirement Income System Reform: Employer Plans, Public Plans and Tax Assisted Savings.

94-03 BILODEAU, M. et AI SLIVINSKI, Volunteering Nonprofit Entrepreneurial Services. (À paraître dans $\underline{\text { Journal of }}$ Economic Behavior and Organization)

94-04 HANEL, Petr, R\&D, Inter-Industry and International Spillovers of Technology and the Total Factor Productivity Growth of Manufacturing Industries in Canada, 1974-1989.

94-05 KALULUMIA, Pene et Denis BOLDUC, Generalized Mixed Estimator for Nonlinear Models: A Maximum Likelihood Approach.

95-01 FORTIN, Mario et Patrice Langevin, L'efficacité du marché boursier face à la politique monétaire.

95-02 HANEL, Petr et Patrice Kayembe YATSHIBI, Analyse de la performance à exporter des industries manufacturières du Québec 1988.

95-03 HANEL, Petr, The Czech Republic: Evolution and Structure of Foreign Trade in Industrial Goods in the Transition Period, 1989-1994. (Paru dans The Vienna Institute Monthly Report, numéro 7, juillet 1995)

95-04 KALULUMIA, Pene et Bernard DÉCALUWÉ, Surévaluation, ajustement et compétitivité externe : le cas des pays membres de la zone franc CFA.

95-05 LATULIPPE, Jean-Guy, Accès aux marchés des pays en développement.

96-01 ST-PIERRE, Alain et Petr HANEL, Les effets directs et indirects de l'activité de R\&D sur la profitabilité de la firme.

96-02 KALULUMIA, Pene et Alain MBAYA LUKUSA, Impact of budget deficits and international capital flows on money demand: Evidence From Cointegration and Error-Correction Model. 

Study Of Selected Countries In Sub-Saharan Africa.

96-04 PARENT, Daniel, Survol des contributions théoriques et empiriques liées au capital humain (A Survey of Theoretical and Empirical Contributions to Human Capital). (Paru dans L'Actualité économique, volume 72. numéro 3, 1996)

96-05 PARENT, Daniel, Matching Human Capital and the Covariance Structure of Earnings

96-06 PARENT, Daniel, Wages and Mobility : The Impact of Employer-Provided Training. (À paraître dans le Journal of Labor Economics)

97-01 PARENT, Daniel, Industry-Specific Capital and the Wage Profile : Evidence From the NLSY and the PSID.

97-02 PARENT, Daniel, Methods of Pay and Earnings: A Longitudinal Analysis

97-03 PARENT, Daniel, Job Characteristics and the Form of Compensation.

97-04 FORTIN, Mario et Michel BERGERON, Jocelyn DUFORT et Pene KALULUMIA, Measuring The Impact of Swaps on the Interest Rate Risk of Financial Intermediaries Using Accounting Data.

97-05 FORTIN, Mario, André LECLERC et Claude THIVIERGE, Testing For Scale and Scope Effects in Cooperative Banks: The Case of Les Caisses populaires et d'économie Desjardins.

97-06 HANEL, Petr, The Pros and Cons of Central and Eastern Europe Joining the EU

00-01 MAKDISSI, Paul et Jean-Yves DUCLOS, Restricted and Unrestricted Dominance Welfare, Inequality and Poverty Orderings

00-02 HANEL, Petr, John BALDWIN et David SABOURIN, Les déterminants des activités d'innovation dans les entreprises de fabrication canadiennes : le rôle des droits de propriété intellectuelle

00-03 KALULUMIA, Pene, Government Debt, Interest Rates and International Capital Flows: Evidence From Cointegration

00-04 MAKDISSI, Paul et Cyril TÉJÉDO, Problèmes d'appariement et politique de l'emploi

00-05 MAKDISSI, Paul et Quentin WODON, Consumption Dominance Curves: Testing for the Impact of Tax Reforms on Poverty

00-06 FORTIN, Mario et André LECLERC, Demographic Changes and Real Housing Prices in Canada.

00-07 HANEL, Petr et Sofiene ZORGATI, Technology Spillovers and Trade: Empirical Evidence for the G7 Industrial Countries.

01-01 MAKDISSI, Paul et Quentin WODON, Migration, poverty, and housing: welfare comparisons using sequential stochastic dominance. Avril 2001. (23 p)

01-02 HUNG Nguyen Manh et Paul MAKDISSI, Infantile mortality and fertility decisions in a stochastic environment. Mars 2001. (12 p).

01-03 MAKDISSI, Paul et Quentin WODON, Fuel poverty and access to electricity: comparing households when they differ in needs Juin 2001. (19 p)

01-04 MAKDISSI, Paul et Yves GROLEAU, Que pouvons-nous apprendre des profils de pauvreté canadiens ? Juillet 2001. (47 p)

01-05 MAKDISSI, Paul et Quentin WODON, Measuring poverty reduction and targeting performance under multiple government programs Août 2001. (16 p)

01-06 DUCLOS, Jean-Yves et Paul MAKDISSI, Restricted inequality and relative poverty. Août 2001. (31 p)

01-07 TÉJÉDO, Cyril et Michel TRUCHON, Serial cost sharing in multidimensional contexts Septembre 2001. (37 p)

01-08 TÉJÉDO, Cyril, Strategic analysis of the serial cost sharing rule with symmetric cost function. Février 2001. $(25 \mathrm{p})$

02-01 DUCLOS, Jean-Yves, Paul MAKDISSI et Quentin WODON, Socially-efficient tax reforms Janvier 2002. (47p)

* Tous ces cahiers de recherche sont disponibles sur notre site WEB (www.usherb.ca/flsh/eco) ou au Centre de documentation de la FLSH A3-330 (UdeS).

Prière d'adresser vos commentaires ou demandes d'exemplaires d'un cahier de recherche antérieur (1976 à 1990) à monsieur Pene KALULUMIA, coordonnateur des Cahiers de recherche du Département d'économique, Tél : 819) 821-7233 Télécopieur : 819) 8217237 Courriel :pkalulum@courrier.usherb.ca

Comments or requests for copies of previous Working Papers (1976 to 1990) should be made to the Working Papers Coordinator at the Département d'économique, Mr. Pene KALULUMIA. Tel: (819) 821-7233

FAX:819) 821-7237 E-mail: pkalulum@courrier.usherb.ca 